\title{
Report on INL Activities for Uncertainty Reduction Analysis of FY11
}

G. Palmiotti

H. Hiruta

M. Salvatores

September 2011

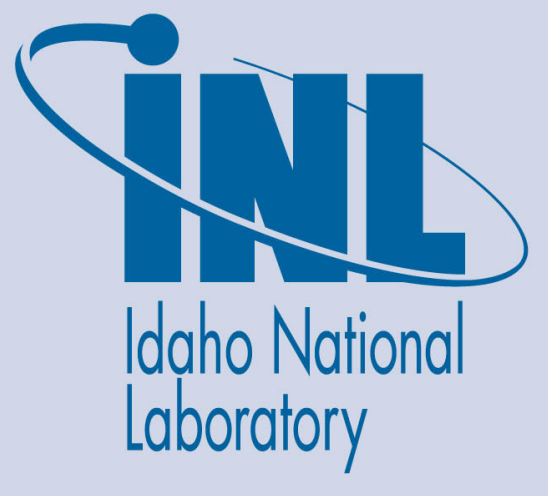

The INL is a U.S. Department of Energy National Laboratory operated by Battelle Energy Alliance 
INL/EXT-11-23283

\title{
Report on INL Activities for Uncertainty Reduction Analysis of FY11
}

\author{
G. Palmiotti \\ H. Hiruta \\ M. Salvatores
}

September 2011

\begin{abstract}
Idaho National Laboratory
Idaho Falls, Idaho 83415
\end{abstract}

http://www.inl.gov

\author{
Prepared for the \\ U.S. Department of Energy \\ Office of Nuclear Energy \\ Under DOE Idaho Operations Office \\ Contract DE-AC07-05ID14517
}




\section{DISCLAIMER}

This information was prepared as an account of work sponsored by an agency of the U.S. Government. Neither the U.S. Government nor any agency thereof, nor any of their employees, makes any warranty, expressed or implied, or assumes any legal liability or responsibility for the accuracy, completeness, or usefulness, of any information, apparatus, product, or process disclosed, or represents that its use would not infringe privately owned rights. References herein to any specific commercial product, process, or service by trade name, trade mark, manufacturer, or otherwise, does not necessarily constitute or imply its endorsement, recommendation, or favoring by the U.S. Government or any agency thereof. The views and opinions of authors expressed herein do not necessarily state or reflect those of the U.S. Government or any agency thereof. 
Report on INL Activities for Uncertainty Reduction Analysis of FY11

September 2011 


\section{SUMMARY}

This report presents the status of activities performed at INL under the ARC Work Package on "Uncertainty Reduction Analyses" that has as a main goal the reduction of uncertainties associated with nuclear data on neutronic integral parameters of interest for the design of advanced fast reactors under consideration by the ARC program.

First, an analysis of experiments was carried out. For both JOYO (the first Japanese fast reactor) and ZPPR-9 (a large size zero power plutonium fueled experiment performed at ANL-W in Idaho) the performance of ENDF/B-VII.0 is quite satisfying except for the sodium void configurations of ZPPR-9, but for which one has to take into account the approximation of the modeling. In fact, when one uses a more detailed model (calculations performed at ANL in a companion WP) more reasonable results are obtained.

A large effort was devoted to the analysis of the irradiation experiments, PROFIL-1 and -2 and TRAPU, performed at the French fast reactor PHENIX. For these experiments a pre-release of the ENDF/B-VII.1 cross section files was also used, in order to provide validation feedback to the CSWEG nuclear data evaluation community.

In the PROFIL experiments improvements can be observed for the ENDF/B-VII.1 capture data in ${ }^{238} \mathrm{Pu}$, ${ }^{241} \mathrm{Am},{ }^{244} \mathrm{Cm},{ }^{97} \mathrm{Mo},{ }^{151} \mathrm{Sm},{ }^{153} \mathrm{Eu}$, and for ${ }^{240} \mathrm{Pu}(\mathrm{n}, 2 \mathrm{n})$. On the other hand, ${ }^{240,242} \mathrm{Pu},{ }^{95} \mathrm{Mo},{ }^{133} \mathrm{Cs}$ and ${ }^{145} \mathrm{Nd}$ capture $\mathrm{C} / \mathrm{E}$ results are worse. For the major actinides ${ }^{235} \mathrm{U}$ and especially ${ }^{239} \mathrm{Pu}$ capture $\mathrm{C} / \mathrm{E}$ 's are underestimated. For fission products, ${ }^{105,106} \mathrm{Pd},{ }^{143,144} \mathrm{Nd}$ and ${ }^{147,149} \mathrm{Sm}$ are significantly underestimated, while ${ }^{101} \mathrm{Ru}$ and ${ }^{151} \mathrm{Sm}$ are overestimated. Other $\mathrm{C} / \mathrm{E}$ deviations from unity are within the combined experimental and calculated statistical uncertainty. From the TRAPU analysis, the major improvement is in the predicted ${ }^{243} \mathrm{Cm}$ build-up, presumably due to an improved ${ }^{242} \mathrm{Cm}$ capture evaluation. The COSMO experiment was also analyzed in order to provide useful feedback on fission cross sections. It was found that ENDF/B-VII.1 ${ }^{238,240} \mathrm{Pu}$ fission cross sections have improved with respect to VII.0 files while ${ }^{242} \mathrm{Pu}$ fission cross section has not.

One major achievement reported in this deliverable is a table, which summarizes all the experiments (148) analyzed so far using ENDF/B-VII.0 cross section data and the best modeling available (in most cases Monte Carlo calculations). The table reports $\mathrm{C} / \mathrm{E}$ 's and associated uncertainties. This table represents the basis for performing a thorough adjustment. However, at this moment sensitivity coefficients, needed to carry out the adjustment, have been computed only for a limited set of experiments. For this reason, it was decided to proceed to a partial adjustment using a very well characterized subset (from the original 148) of experiments, including availability of correlation terms among the selected experiments. This subset of experiments is the one selected and analyzed in the framework of the WPEC OECD/NEA Subgroup 33.

The adjustment was performed using the 33 energy group covariance data matrix COMMARA 2.0 and very satisfying results were obtained both in terms of new C/E's after adjustment and $\chi^{2}$ test for statistical consistency. More importantly, the uncertainties of the major cross sections affected in the adjustment $\left({ }^{235} \mathrm{U}\right.$ capture, ${ }^{238} \mathrm{U}$ inelastic, ${ }^{239} \mathrm{Pu}$ inelastic and fission spectrum) show major improvements after adjustment. These are the quantities that are more relevant to this work as they will produce, when used in an uncertainty evaluation, significant reductions. 
Report on INL Activities for Uncertainty Reduction Analysis of FY11

September 2011 


\section{CONTENTS}

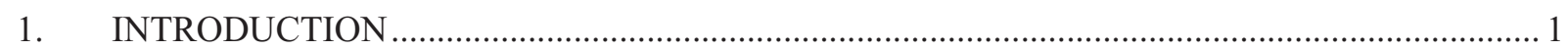

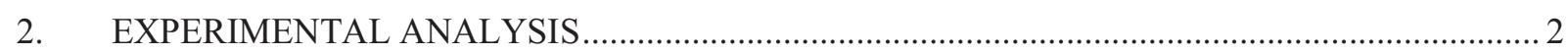

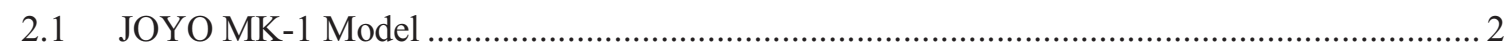

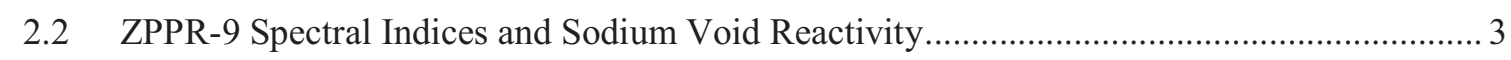

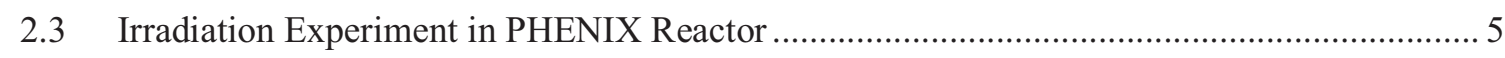

2.3.1 Evaluation of One-Group Cross Sections by Monte Carlo Method............................ 8

2.3.2 Depletion analysis with MCNP cross sections..................................................... 9

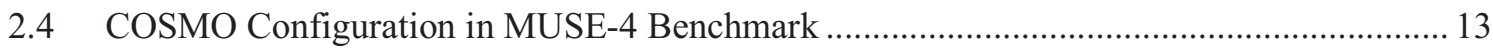

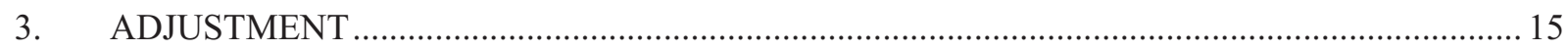

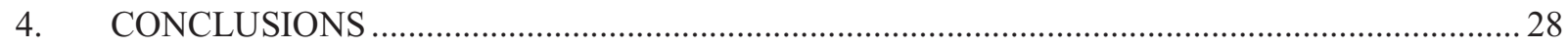

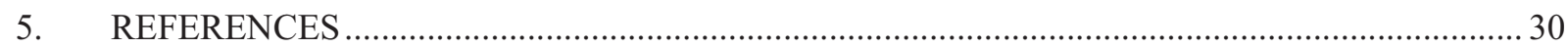


Report on INL Activities for Uncertainty Reduction Analysis of FY11

September 2011 
Report on INL Activities for Uncertainty Reduction Analysis of FY11

September 2011

viii 


\section{INTRODUCTION}

The work scope of this project related to the Work Packages of "Uncertainty Reduction Analyses" with the goal of reducing nuclear data uncertainties is to produce a set of improved nuclear data to be used both for a wide range of validated advanced fast reactor design calculations, and for providing guidelines for further improvements of the ENDF/B files (i.e. ENDF/B-VII, and future releases).

Recent extensive sensitivity/uncertainty studies, performed within an international OECD-NEA initiative, have quantified for the first time the impact of current nuclear data uncertainties on design parameters of the major FCR\&D and GEN-IV systems, and in particular on Na-cooled fast reactors with different fuels (oxide or metal), fuel composition (e.g. different Pu/TRU ratios) and different conversion ratios. These studies have pointed out that present uncertainties on the nuclear data should be significantly reduced, in order to get full benefit from the advanced modeling and simulation initiatives.

Nuclear data plays a fundamental role in performance calculations of advanced reactor concepts. Uncertainties in the nuclear data propagate into uncertainties in calculated integral quantities, driving margins and costs in advanced system design, operation and safeguards. This package contributes to the resolution of technical, cost, safety, security and proliferation concerns in a multi-pronged, systematic, science-based R\&D approach. The Nuclear Data effort identifies and develops small scale, phenomenonspecific experiments informed by theory and engineering to reduce the number of large, expensive integral experiments. The Nuclear Data activities are leveraged by effective collaborations between experiment and theory, between DOE programs and offices, at national laboratories and universities, both domestic and international.

The primary objective is to develop reactor core sensitivity and uncertainty analyses that identify the improvement needs of key nuclear data which would facilitate fast spectrum system optimization and assure safety performance. The inclusion of fast spectrum integral experiment data is key to minimizing the impact of nuclear data uncertainties on reactor core performance calculations, thus providing the best nuclear data needs assessment.

This report presents the status of activities performed at INL under the ARC Work Package previously mentioned. First, analyses of a number of experiments, among those selected in the previous fiscal years and available, are presented making use of ENDF/B-VII data. These experiments include: evaluation of critical mass of the JOYO (MK-1configuration) reactor, update of ZPPR-9 assembly for spectral indices and sodium void configurations, and irradiation experiments performed at the PHENIX reactor. These last experiments include PROFIL-1, PROFIL-2, and TRAPU experiments. For these irradiation experiments, besides, the standard analysis using ENDF/B-VII.0 results using a pre-release (version $\beta 3$ ) of ENDF/BVII.1 are also provided. Then, a partial adjustment using the subset of integral experiments adopted by the OECD/NEA WPEC Subgroup 33 and utilizing the COMMARA 2.0 covariance matrix is presented. Finally in the conclusions the future work for next fiscal year is outlined. 


\section{EXPERIMENTAL ANALYSIS}

This section of the report presents the progress in the analysis of selected integral experiments using Monte Carlo code MCNP5 [1] with ENDF/B-VII cross sections library. For analyses of irradiation experiments in PHENIX reactor and COSMO configuration in MUSE-4 benchmark project, recently prereleased version of ENDF/B-VII.1 ( $\beta 3$ ) has been used and compared to the results obtained with the previous version of ENDF/B-VII. This was done on explicit request from the nuclear evaluator community (CSWEG) in order to validate the cross section files before final release.

\section{$2.1 \quad J O Y O$ MK-1 Model}

JOYO is the first experimental fast reactor constructed in Japan. The core consists of mixed-oxide fuel assembly region surrounded by radial and axial blanket of depleted uranium-oxide. There are two types of core configurations in JOYO MK-I, 64 fuel-subassembly and 70 fuel-subassembly configurations. We have selected and analyzed the 64 fuel-subassembly configuration. The radial cross sectional view of the 64 fuel-subassembly JOYO MK-I model is shown in Figure 1. The corresponding cylindrical model has been also developed. Its cross sectional view is shown in Figure 2.

The measured multiplication factor at the core temperature of $250{ }^{\circ} \mathrm{C}\left(523.15{ }^{\circ} \mathrm{K}\right)$ is available from the report [2]. ENDF/B-VII.0 cross sections at several temperatures were converted into ACE format by NJOY from $300{ }^{\circ} \mathrm{K}$ to $2800{ }^{\circ} \mathrm{K}$ with $50{ }^{\circ} \mathrm{K}$ interval. Therefore, there were no cross sections at $250{ }^{\circ} \mathrm{C}$. In order to take into account the closest Doppler Effect to that corresponds to the core temperature of 250 ${ }^{\circ} \mathrm{C}$, we performed calculations at two closest temperatures (i.e., $500{ }^{\circ} \mathrm{K}$ and $550{ }^{\circ} \mathrm{K}$ ). After that, $k_{\text {eff }}$ at 250 ${ }^{\circ} \mathrm{C}$ was obtained by the linear interpolation of two $k_{\text {eff }}$.

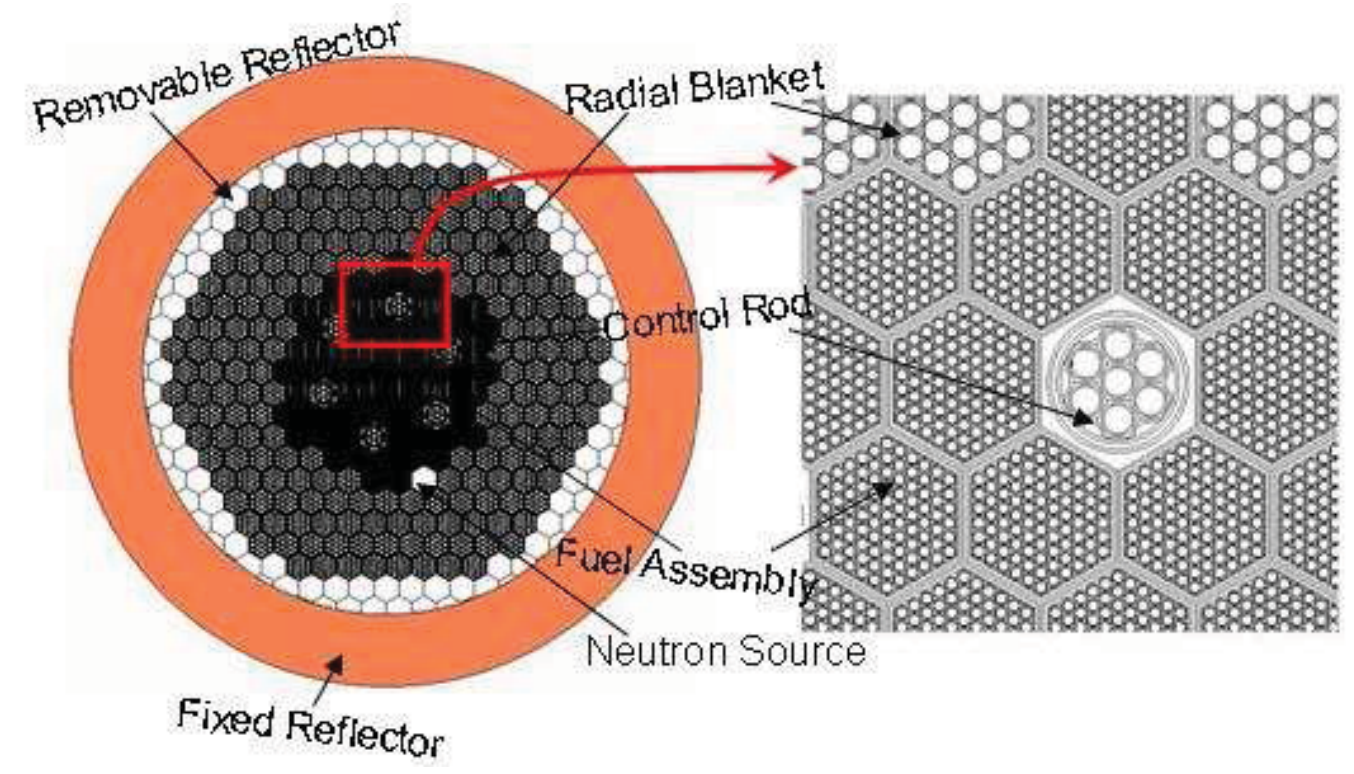

Figure 1: Radial cross sectional view of detailed JOYO MK-1 model with 64 fuel sub-assemblies. 


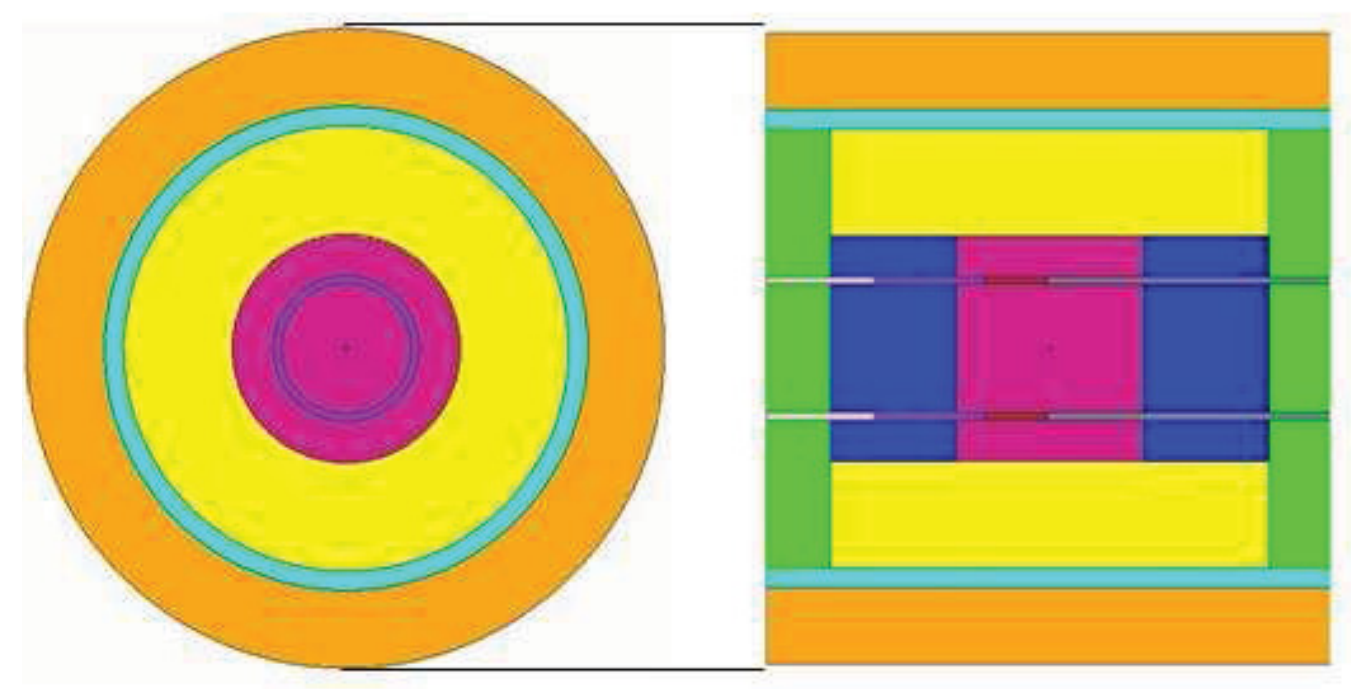

Figure 2: Cylindrical JOYO MK-1 model.

Table I shows calculated $k_{\text {eff }}$ for JOYO MK-1 models. As seen in this table, $k_{\text {eff }}$ calculated with detailed model agrees within the statistical uncertainty of the experimental value.

Table I: Calculated $k_{\text {eff }}$ for JOYO MK-1 models.

\begin{tabular}{|c|c|c|c|}
\hline Core Temp. $\left[{ }^{\circ} \mathrm{K}\right]$ & Experiment & Detailed Model & Cylindrical Model \\
\hline 500 & & $0.99881 \pm 10 \mathrm{pcm}$ & $1.00207 \pm 13 \mathrm{pcm}$ \\
\hline $523.15\left(250^{\circ} \mathrm{C}\right)$ & $1.00105 \pm 180 \mathrm{pcm}$ & $0.99851 \pm 9 \mathrm{pcm}$ & $1.00186 \pm 13 \mathrm{pcm}$ \\
\hline 550 & & $0.99816 \pm 9 \mathrm{pcm}$ & $1.00161 \pm 13 \mathrm{pcm}$ \\
\hline
\end{tabular}

\subsection{ZPPR-9 Spectral Indices and Sodium Void Reactivity}

The ZPPR-9 experiments were conducted as a part of JUPITER program in order to provide integral reactor parameters for conventional mixed-oxide-fueled two-zone liquid metal fast breeder reactors (LMFBRs) of about 650 MWe. The ZPPR-9 assembly is a cylindrical core consisting of two clean homogeneous zones. There is no control-rod position. Last year a simplified cylindrical model was developed for MCNP5 and ERANOS [6] and the core multiplication factor was compared. In this year, we further extended this simplified MCNP model and analyzed spectral indices and sodium void reactivities. These results were then utilized in order to calculate corrective factors (from fully detailed configurations to simplified ones) for the adjustment exercise of the OECD/NEA WPEC Subgroup 33 (see next chapter).

Figure 3 shows the ZPPR-9 R-Z geometry for the spectral index calculations. A point detector was set at the center of the core (axially located $9.708 \mathrm{~cm}$ above the core midplane). Calculated spectral indices along with experimental values are shown in Table II. The major source of discrepancy from the experimental value is the approximation of MCNP geometry which is R-Z geometry 


\section{Report on INL Activities for Uncertainty Reduction Analysis of FY11}

September 2011

4

Figure 4 shows the ZPPR-9 R-Z geometry for the Na void reactivity calculations. We consider two types of void steps: Step 3, which is non-leakage dominated configuration, and Step 5, which is leakage enhanced configuration. The effective delayed neutron fraction used for these calculations is $3.550 \times 10^{-3}$. Table III shows comparison of Na Void Reactivity for ZPPR-9. There is severe discrepancy observed in STEP 5 configuration. This is again mainly caused by the approximation of MCNP geometry.

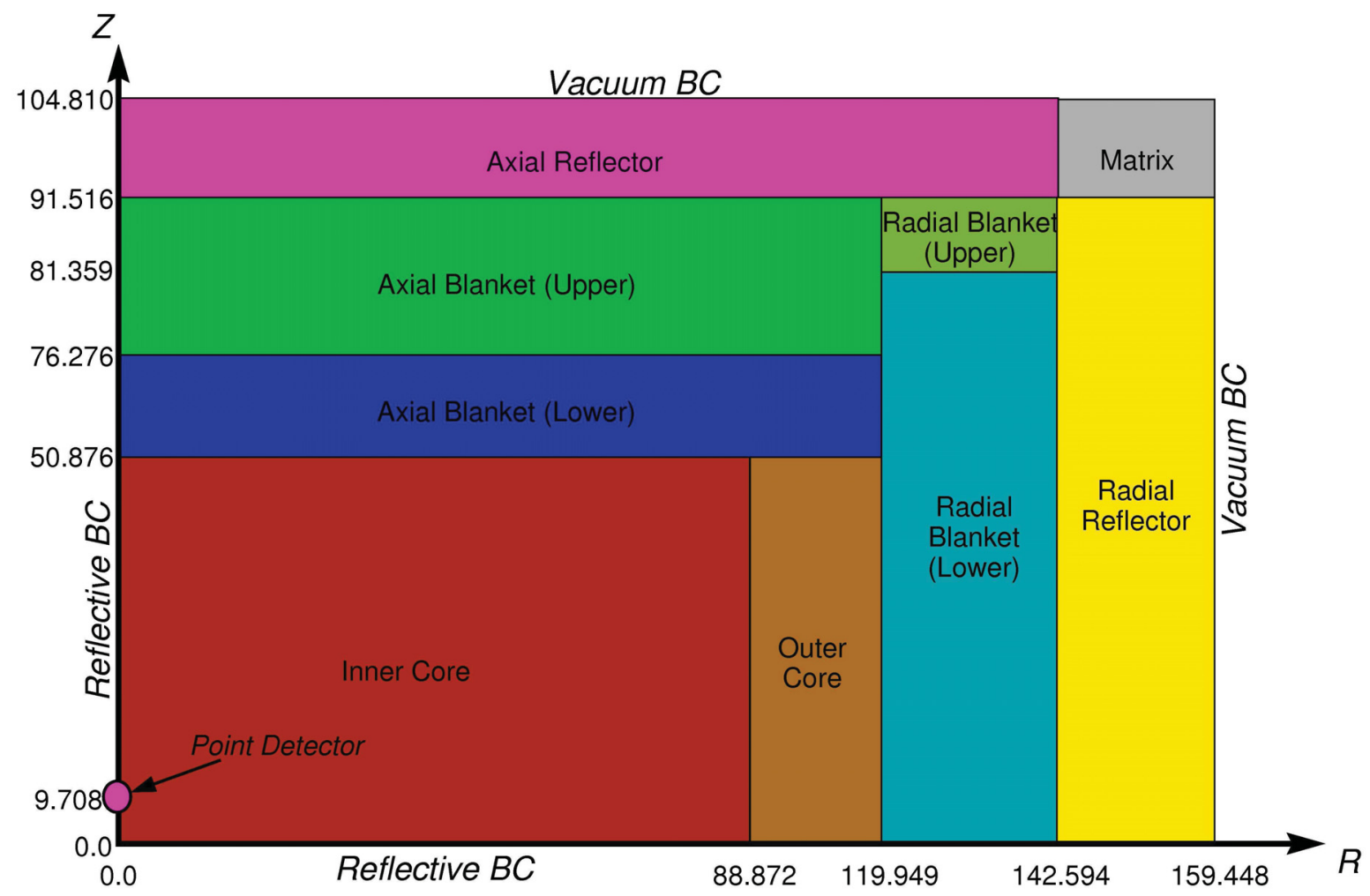

Figure 3: ZPPR-9 R-Z geometry for the spectral index calculations.

Table II: Comparison of spectral indices for ZPPR-9

\begin{tabular}{|c|c|c|c|}
\hline Spectral Index & MCNP5 R-Z Model & Experiment & C/E \\
\hline$\left.\sigma_{\mathrm{f}}\left({ }^{238} \mathrm{U}\right) / \sigma_{\mathrm{f}}{ }^{235} \mathrm{U}\right)$ & $0.0198 \pm 0.0002$ & $0.0207 \pm 2.7 \%$ & $0.9565 \pm 2.9 \%$ \\
\hline$\sigma_{\mathrm{f}}\left({ }^{239} \mathrm{Pu}\right) / \sigma_{\mathrm{f}}\left({ }^{235} \mathrm{U}\right)$ & $0.9091 \pm 0.0041$ & $0.9225 \pm 2.0 \%$ & $0.9855 \pm 2.1 \%$ \\
\hline$\sigma_{\gamma}\left({ }^{238} \mathrm{U}\right) / \sigma_{\mathrm{f}}\left({ }^{235} \mathrm{U}\right)$ & $0.1382 \pm 0.0009$ & $0.1296 \pm 1.9 \%$ & $1.0664 \pm 2.0 \%$ \\
\hline
\end{tabular}




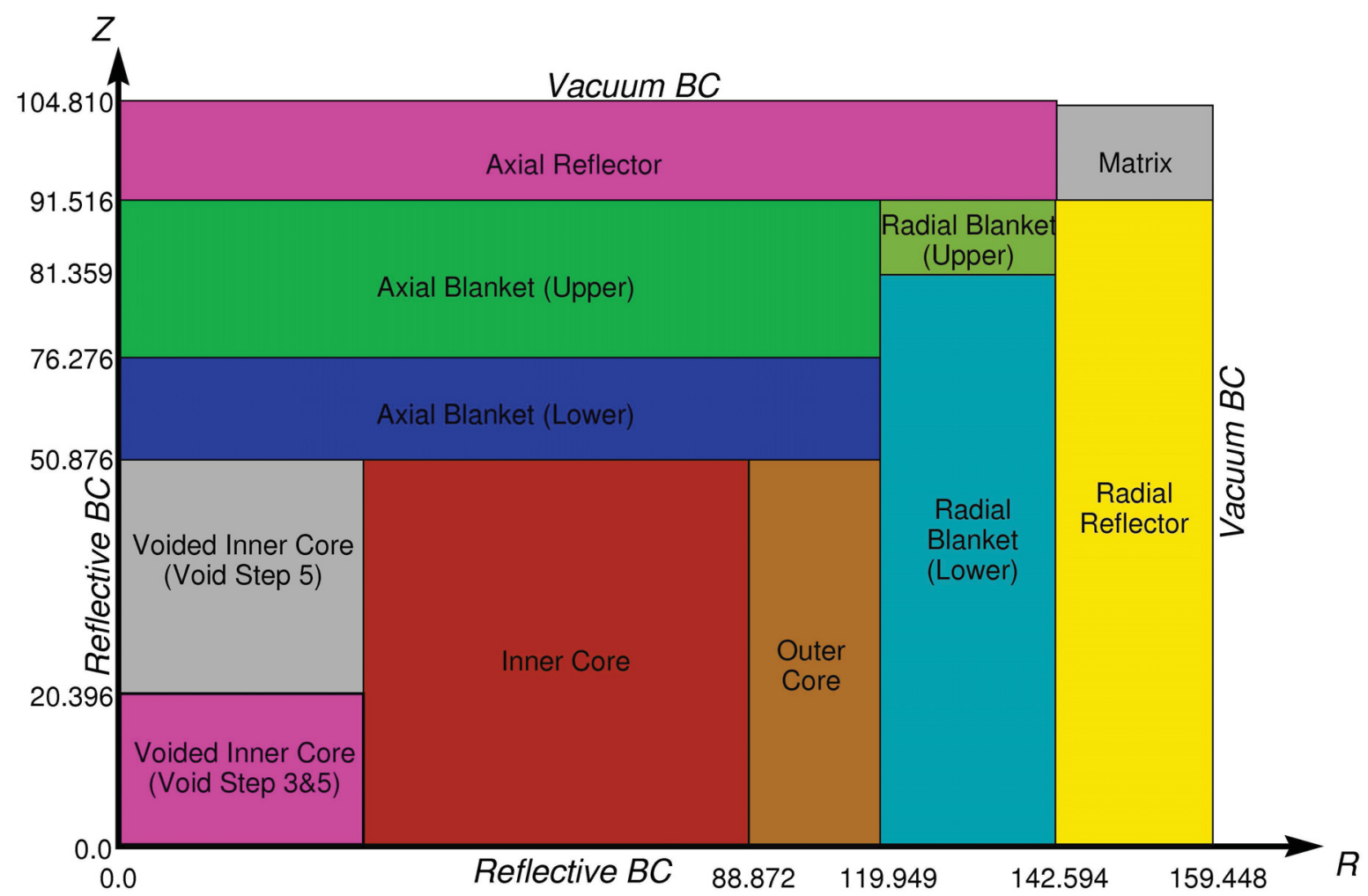

Figure 4: ZPPR-9 R-Z geometry for the Na void reactivity calculations.

Table III: Comparison of Na Void Reactivity for ZPPR-9

\begin{tabular}{|c|c|c|c|}
\hline Na Void Step & $\begin{array}{c}\text { MCNP5 R-Z Model } \\
\text { [cents] }\end{array}$ & $\begin{array}{c}\text { Experiment } \\
\text { [cents] }\end{array}$ & C/E \\
\hline Step 3 & $28.91 \pm 1.64$ & $29.18 \pm 0.51$ & $0.9907 \pm 0.0588$ \\
\hline Step 5 & $38.73 \pm 1.63$ & $31.30 \pm 0.53$ & $1.2374 \pm 0.0561$ \\
\hline
\end{tabular}

\subsection{Irradiation Experiment in PHENIX Reactor}

Advanced nuclear systems and associated fuel cycles need accurate cross section data to provide a reliable assessment of their performance. Closed fuel cycles with the objective of waste minimization imply, from a physics point of view:

- A high content of minor actinides in the reactor core and in the fuel cycle;

- A high Fissile/Fertile isotope content in the core fuel;

- A variable, and potentially degraded, Pu isotopic vector in the fuel cycle;

- Lower fuel density to achieve lower conversion ratios

Basic data are available for TRU (transuranic) isotopes (up to Cf) but a validation is needed in order to quantify their reliability. The high amount of minor actinides (MA) foreseen in advanced fuel cycle 
systems requires specific validation work, especially for capture and fission cross sections of such isotopes.

Such validation is traditionally done through the use of differential and integral experiments, and uncertainty assessment. Information that can be gathered on MA's from experiment comes mostly from small sample irradiation, reactivity oscillation, and fission and capture rate measurements. Separate isotope sample and fuel pin irradiations in power reactors also provide unique sources of measurement data.

Results from analyses of such experiments provide indications to nuclear data evaluators for improving the quality of basic files, and to assess their impact on advanced fuel cycles. Experimental data from the PROFIL and TRAPU irradiation experiments [3], performed at the CEA PHENIX fast reactor, provide clean and precise information on both cross section data and transmutation rates of actinides. These data are essential for the validation of the methods and data to be used in advanced fuel cycles where transmutation systems will be used to reduce the existing inventory of nuclear waste.

During the PROFIL-1 experiment (see Figure. 5), performed in 1974, a pin containing 46 samples, including fission products plus major and minor actinides (Uranium, Plutonium, and Americium isotopes) was irradiated in the PHENIX reactor for the first three cycles, corresponding to a total of 189.2 fullpower days. The experimental pin was located in the central subassembly of the core, and in the third row of pins inside the subassembly. This location is far away from neutronic perturbations allowing clear irradiation conditions. Following the reactor irradiation, mass spectroscopy was then used, with simple or double isotopic dilution and well-characterized tracers to measure isotopic concentrations. The experimental uncertainty obtained with this method is relatively small.

The second part of the PROFIL irradiation campaign (PROFIL-2, Figure 6) took place in 1979. During this experiment two standard pins, each containing 42 separated capsules of fission products plus major and minor actinides (Uranium, Plutonium, Americium and Neptunium isotopes), were irradiated for four cycles (the 17th through 20th) in the PHENIX reactor. As for PROFIL-1, chemical and mass spectrometry analyses have been subsequently performed to determine the post-irradiation isotopic concentrations.

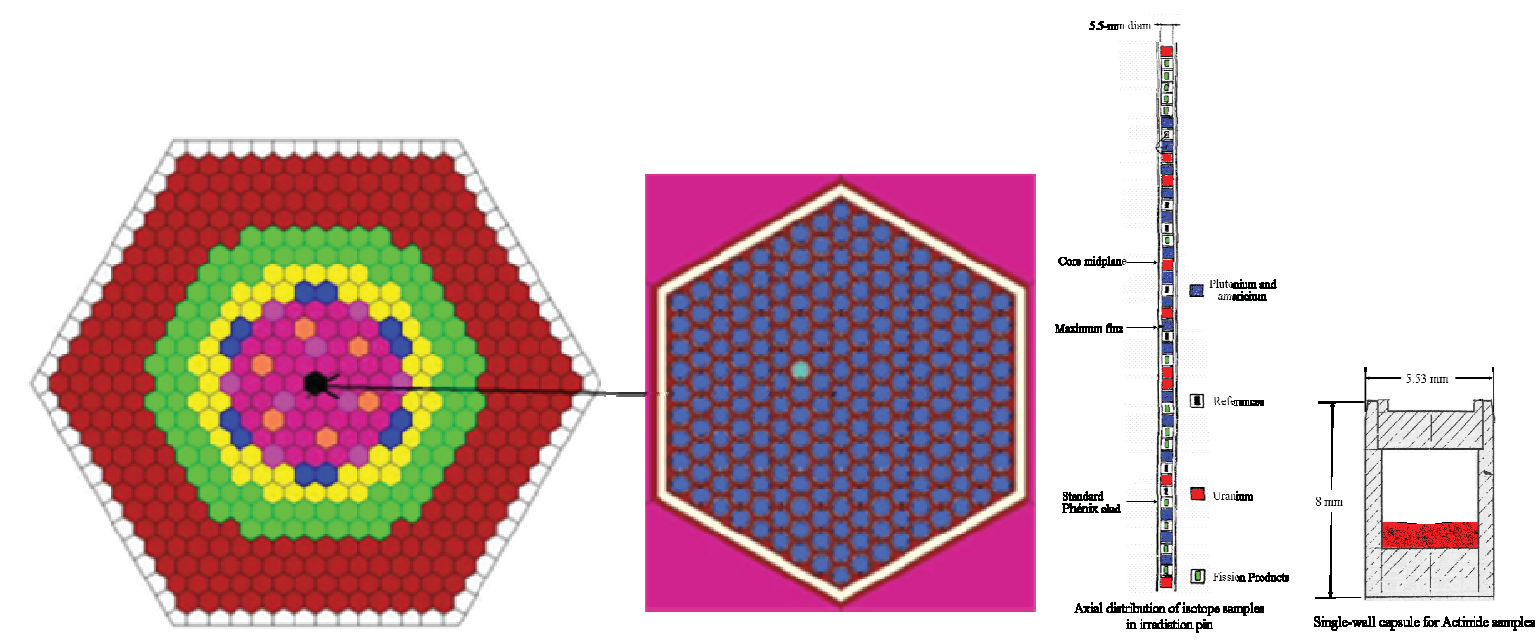

Figure 5: PROFIL-1 irradiation experiment in the French fast reactor PHENIX. 


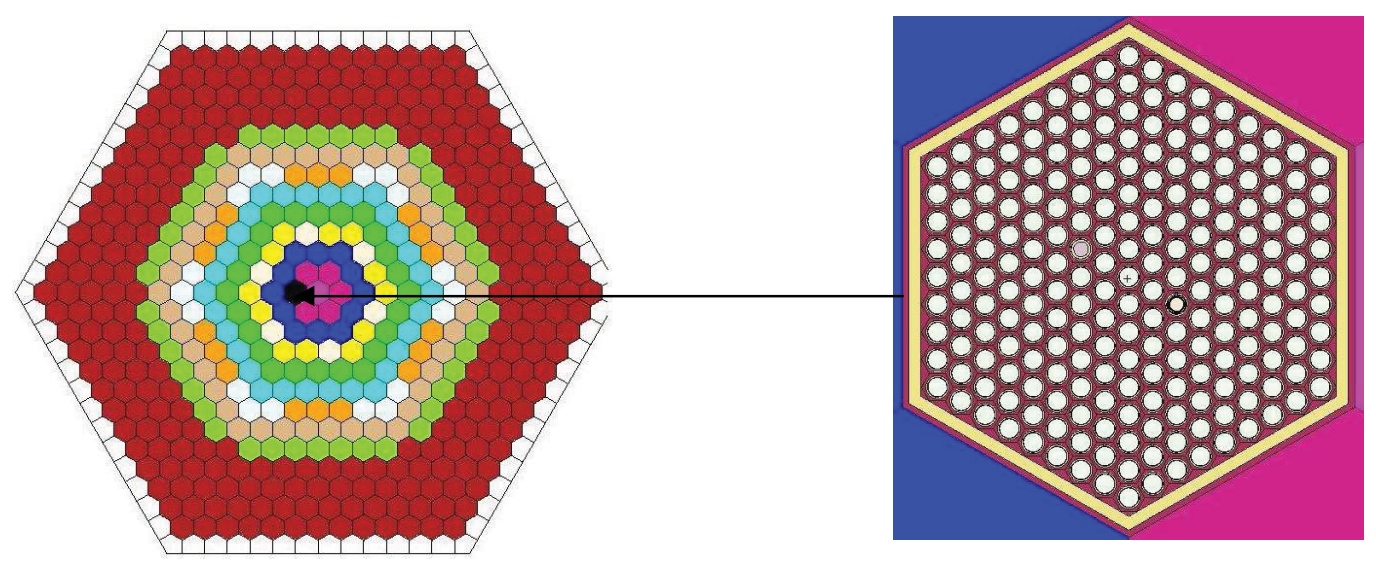

(a) Radial configuration during PROFIL-2 experiment

(b) Subassembly containing irradiated samples

Figure 6: Radial cross sectional view of the PROFIL-2 model by MCNP5.

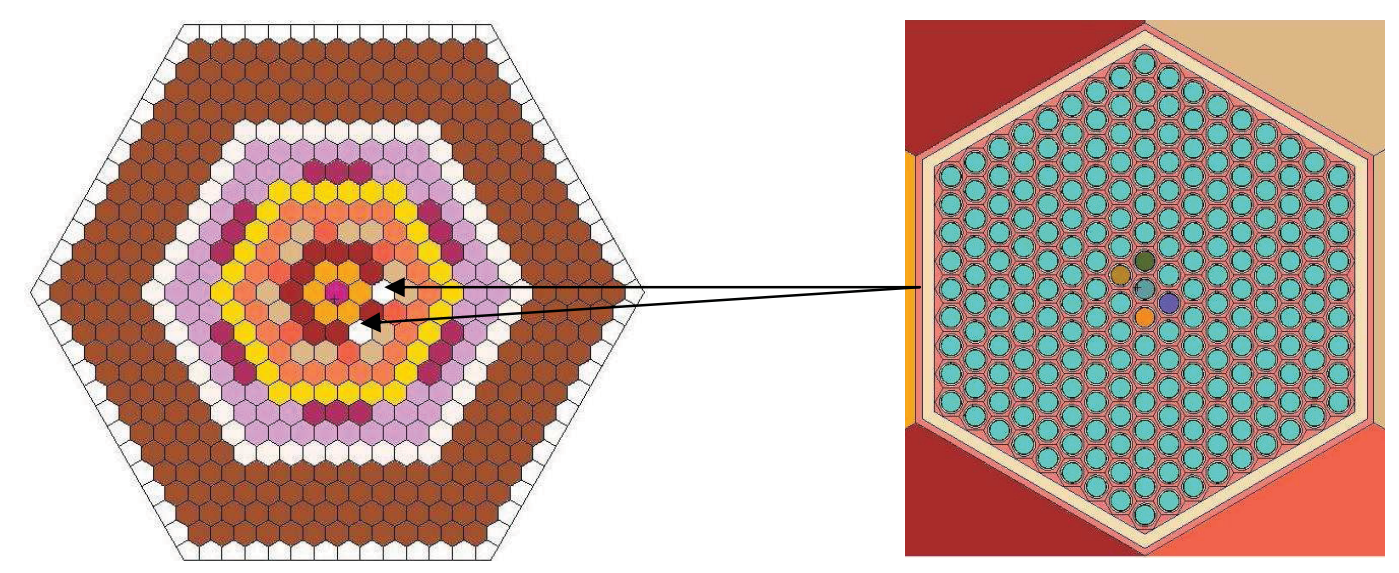

(a) Radial configuration during TRAPU experiment

(b) Subassembly containing irradiated samples

Figure 7: Radial cross sectional view of the TRAPU model by MCNP5.

The TRAPU experiment (Figure 7) consisted of a six-cycle irradiation (10th to 15th) of mixed-oxide pins containing plutonium of different isotopic compositions but heavily loaded in the higher isotopes $\left({ }^{240,241,242} \mathrm{Pu}\right)$ compared to typical PHENIX fuel. In the third assembly ring there are two subassemblies having total of 10 irradiated fuel pins (5 each). Unlike other two experiments, each irradiated fuel pin has only one sample which has the same size as that of ordinal fuel pin.

After irradiation, $20 \mathrm{~mm}$ tall samples were cut from the pins (both fuel and clad) and put into a solution in order to determine the fuel composition by nuclide. ${ }^{148} \mathrm{Nd}$ was used as a burn-up indicator as it is a stable fission product with a small capture cross section, thereby enabling accurate determination of the number of fission reactions that took place in the sample. Again, isotopic data were obtained using mass spectrometry techniques, with simple or double isotopic dilution and well-characterized tracers. 


\subsubsection{Evaluation of One-Group Cross Sections by Monte Carlo Method}

In order to perform three-dimensional burn-up Monte Carlo calculations, it is important to obtain accurate and statistically reliable one-group cross sections for each irradiated sample that are to be used for solving the Bateman equations. Unlike other PROFIL-1\&2 experiments, each irradiated fuel pin for TRAPU experiment has only one sample which has the same size as that of ordinal fuel pin. The large volume of irradiated samples makes Monte Carlo calculations much easier to obtain statistically reliable tallies. However, it is extremely difficult to obtain statistically reliable results for PROFIL-1\&2 since the size of each sample is very small $\left(\sim 0.06 \mathrm{~cm}^{3}\right)$, and some of reactions (e.g., $\left.(\mathrm{n}, 2 \mathrm{n}),(\mathrm{n}, 3 \mathrm{n})\right)$ are caused by very fast neutrons $(5 \mathrm{MeV} \sim)$ which are usually not well populated. Moreover, it is not straightforward to perform variance reduction in criticality calculations. Thus, we came up with a calculation procedure that uses MCNP's surface source capability (Figure 8). In this approach, first, a full-core criticality calculation is performed with the surface source write (SSW) card in order to generate the binary source file containing the surface and fission volume sources around and in the irradiated fuel samples, respectively. This source file is used to perform the fixed source calculation with the reduced geometry modeling only the irradiated fuel pin. The fixed source calculation can be performed with only the recorded particles from the full-core criticality calculation. If the number of recorded source particles is small, then it is not feasible to obtain statistically reliable solutions even with variance reduction techniques. In order to resolve this problem, we wrote a program that duplicates the recorded information of source particles. However, the number of duplications is limited because adding additional source particles enlarges the size of the source file. To address this issue, we performed several fixed source calculations by skipping random numbers corresponding to the number of histories for each run. After finishing all fixed source calculations, the solutions were collected, and then the batch statistics was taken. For the results obtained using ENDF/B-VII.1 ( $\beta 3$ version) data, the same recorded surfaces histories obtained with ENDF/B-VII.0 data were used. This assumption is justified as the cross section data for the major actinides comprising the PHENIX reactor fuel did not change significantly between ENDF/B-VII.0 and VII.1.

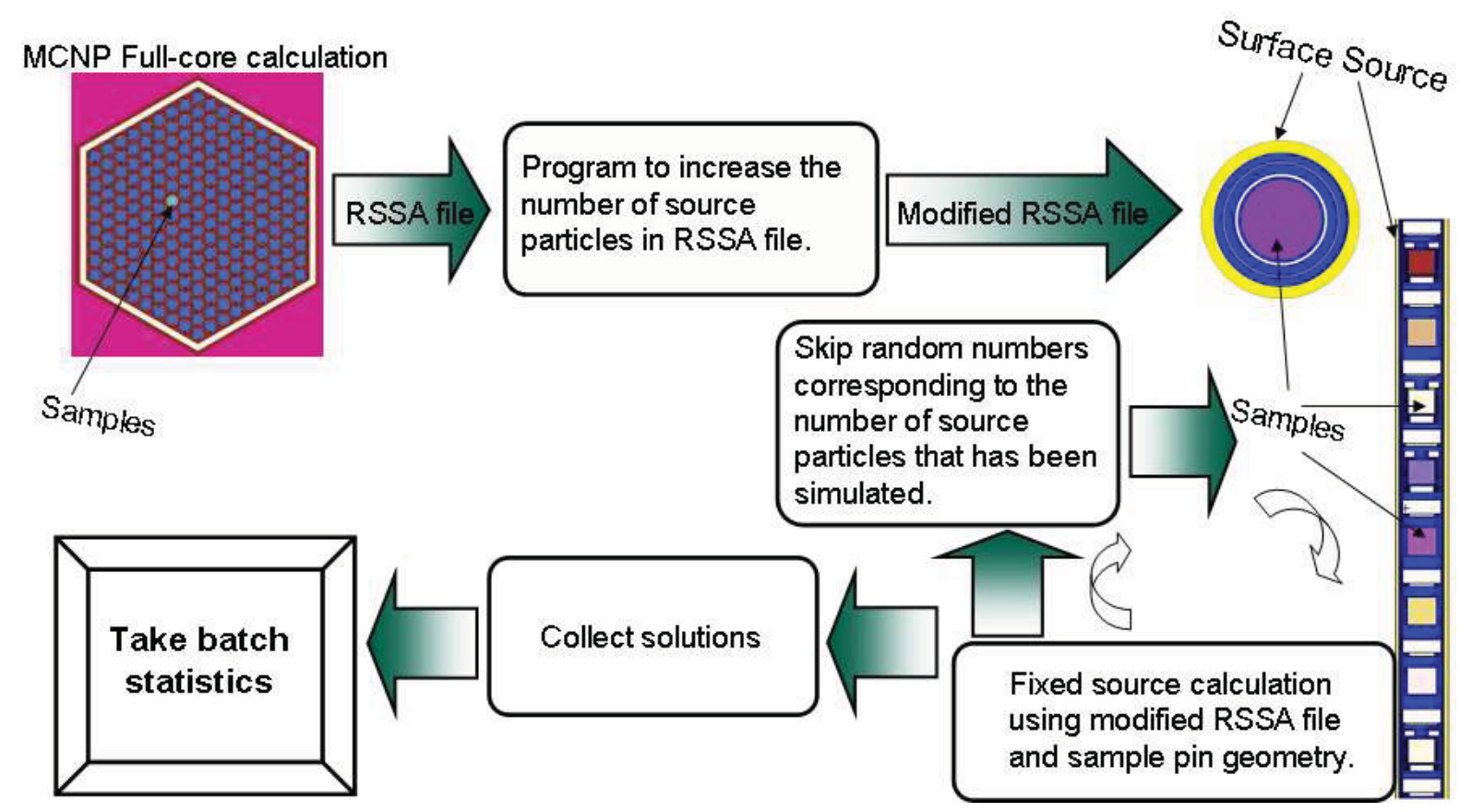

Figure 8: Procedure for calculating one-group cross sections for PROFIL-1 \& 2 by MCNP. 


\subsubsection{Depletion analysis with MCNP cross sections}

The "experimental" axial flux distribution has been provided by the French reports and has been derived by measurements of reaction rates at different places and times. Because of the differences between the experimental and calculated axial flux distributions, a comparison on the Neodymium production for the samples of ${ }^{235} \mathrm{U}$ was performed using the two distributions. The results indicated that the experimental distribution provides a consistent (almost constant) set of C/E's, while the calculated one shows a drift in the bottom part. Based on this observation, it was decided that in the analysis we would use the experimental axial distribution. The likely reason for the observed discrepancy has to be attributed to the lack of information on the control rod movement during the cycles, and the actual flux calculations were performed with a fixed average control rod position.

For what regards PROFIL-2 no clear "experimental" information was provided by the French documentation; therefore, it was decided to use the calculated axial distribution. For TRAPU the value (there is no axial distribution in this case, as we are talking of a $2 \mathrm{~cm}$ piece at the midplane of the reactor) provided by the French documentation was used.

Next step was to correctly normalize the isotope build up results to the actual values of the fluence (and hence eliminate the uncertainty in the irradiation history). To this latter purpose the neodymium production in the ${ }^{235} \mathrm{U}$ samples has been calculated and compared with the correspondent experimental values. The corrective factor, by which the experimental fluxes are divided, has been subsequently derived. The normalization values used in the successive analysis are: 1.047 for PROFIL-1, 1.021 for PROFIL-2, and 1.1436 for TRAPU.

Depletion calculations have been carried out using the NUTS [4] code in order to evaluate the isotope build up. The one group cross sections from the MCNP calculations and normalized fluxes were provided as inputs for the depletion calculations. The information that can be gathered from the post-irradiation analysis is related to the evaluation of the reaction rates (mainly capture and (n,2n) rates) for a given isotope. In particular, the analysis of the experiment is based on the relation existing between the burn-up dependent variations of the atom number densities and the microscopic cross-sections. For isotopes for which the descendant, obtained via neutron capture, is stable or has a long radioactive period, the most accurate experimental technique for obtaining information on the integral capture cross section is to determine the variation in composition that results from high-flux irradiation of a pure sample. Capture and $(\mathrm{n}, 2 \mathrm{n})$ reaction rates for an isotope of mass $\mathrm{A}$, which has received a total fluence of $\tau$, can be evaluated by the measurement of ratios of concentrations using Equations (1) and (2) respectively:

$$
\begin{aligned}
& \boldsymbol{\sigma}_{(c), A} \cdot \boldsymbol{\tau} \cdot f(\boldsymbol{\tau}) \cong \frac{\Delta N_{A+1}}{N_{A}}=\frac{N_{A+1}(\boldsymbol{\tau})}{N_{A}(\boldsymbol{\tau})}-\frac{N_{A+1}(0)}{N_{A}(0)} \\
& \boldsymbol{\sigma}_{(n, 2 n), A} \cdot \boldsymbol{\tau} \cdot f(\boldsymbol{\tau}) \cong \frac{\Delta N_{A-1}}{N_{A}}=\frac{N_{A-1}(\boldsymbol{\tau})}{N_{A}(\boldsymbol{\tau})}-\frac{N_{A-1}(0)}{N_{A}(0)}
\end{aligned}
$$

where $f(\tau)$ is a correcting factor which takes into account the physical phenomena different from capture (or $(\mathrm{n}, 2 \mathrm{n})$ reactions) that the considered isotope A can experience during the irradiation. Because of its definition $f(\tau)$ is a measure of the fertile or fissile properties of a given isotope, being lower and higher than one for fertile and fissile isotopes respectively. It can be evaluated by a time dependent calculation, as follows: 


$$
f(\tau)=\left[\frac{N_{A+1}^{(\tau)}}{N_{A}^{(\tau)}}-\frac{N_{A+1}^{(0)}}{N_{A}^{(0)}}\right] \times \frac{1}{\sigma_{C A} \cdot \tau_{\text {calc. }}}
$$

In Equation (3), $\sigma_{\mathrm{CA}}$ and $\tau_{\text {calc }}$ represent the one-group capture cross section for the isotope $\mathrm{A}$ and the calculated fluence, respectively.

This approach works very well when we are considering a reaction rate that is dominant in the formation of the measured resulting isotope (i. e., capture cross section) but it will attribute the same $\mathrm{C} / \mathrm{E}$ also when the reaction rate is not dominant like in the case of an $(n, 2 n)$ cross section. In order to avoid this problem a slightly different approach was adopted. We correct the experimental density variation by a calculated quantity that takes out the variation due to all the phenomena other than the reaction rate that we are considering:

$$
\boldsymbol{\sigma}_{(c), A} \cdot \boldsymbol{\tau} \cdot \cong \frac{{ }^{c o r r} \Delta N_{A+1}}{N_{A}}=\frac{{ }^{e x p} \Delta N_{A+1}(\boldsymbol{\tau})-\left({ }^{c a l c} \Delta N_{A+1}-N_{A}^{(0)} \boldsymbol{e}^{-\boldsymbol{\sigma \tau}}\right)}{N_{A}}
$$

where ${ }^{e x p} \Delta N_{A+1}(\tau)$ is the experimental measured density variation, and calc $\Delta N_{A+l}$ is the calculated one.

In the end, Eq. 4 was used to derive an initial guess for the unknown experimental cross section and then this latter is computed by changing its value until the final measured experimental densities were matched. Using this approach C/E's were calculated for the sample isotope build up.

Tables IV-VIII show a comparison of the C/E's for the different irradiation experiments. In the PROFIL experiments, improvements can be observed for the ENDF/B-VII.1 capture data in ${ }^{238} \mathrm{Pu},{ }^{241} \mathrm{Am}$, ${ }^{244} \mathrm{Cm},{ }^{97} \mathrm{Mo},{ }^{151} \mathrm{Sm},{ }^{153} \mathrm{Eu}$, and for ${ }^{240} \mathrm{Pu}(\mathrm{n}, 2 \mathrm{n})$. On the other hand, ${ }^{240,242} \mathrm{Pu},{ }^{95} \mathrm{Mo},{ }^{133} \mathrm{Cs}$ and ${ }^{145} \mathrm{Nd}$ capture $\mathrm{C} / \mathrm{E}$ results are worse. For the major actinides ${ }^{235} \mathrm{U}$ and especially ${ }^{239} \mathrm{Pu}$ capture C/E's are underestimated. For fission products, ${ }^{105,106} \mathrm{Pd},{ }^{143,144} \mathrm{Nd}$ and ${ }^{147,149} \mathrm{Sm}$ are significantly underestimated, while ${ }^{101} \mathrm{Ru}$ and ${ }^{151} \mathrm{Sm}$ are overestimated. Other $\mathrm{C} / \mathrm{E}$ deviations from unity are within the combined experimental and calculated statistical uncertainty. From the TRAPU analysis, the major improvement is in the predicted ${ }^{243} \mathrm{Cm}$ build-up, presumably due to an improved ${ }^{242} \mathrm{Cm}$ capture evaluation. 
Table IV: C/E's for PROFIL-1 irradiation experiment.

\begin{tabular}{|c|c|c|c|}
\hline \multirow{2}{*}{$\sigma$} & \multicolumn{3}{|c|}{$\mathrm{C} / \mathrm{E}$} \\
\hline & VII.0 & VII.1 & Exp. Unc. \\
\hline$\sigma_{\text {capt }}$ U-235 & 0.948 & 0.948 & $1.7 \%$ \\
\hline$\sigma_{\text {capt }}$ U-238 & 0.972 & 0.972 & $2.3 \%$ \\
\hline$\sigma_{\text {capt }} \mathrm{Pu}-238$ & 1.299 & 1.135 & $4.0 \%$ \\
\hline$\sigma_{\text {capt }}$ Pu-239 & 0.906 & 0.906 & $3.0 \%$ \\
\hline$\sigma_{\mathrm{n}, 2 \mathrm{n}}$ Pu-239 & 0.745 & 0.745 & $15.0 \%$ \\
\hline$\sigma_{\text {capt }}$ Pu-240 & 0.964 & 0.945 & $2.2 \%$ \\
\hline$\sigma_{\mathrm{n}, 2 \mathrm{n}} \mathrm{Pu}-240$ & 0.779 & 1.084 & $15.0 \%$ \\
\hline$\sigma_{\text {capt }} \mathrm{Pu}-241$ & 0.950 & 0.947 & $4.1 \%$ \\
\hline$\sigma_{\text {capt }} \mathrm{Pu}-242$ & 1.061 & 1.120 & $3.5 \%$ \\
\hline$\sigma_{\text {capt }}$ Am-241 & 0.968 & 0.984 & $1.7 \%$ \\
\hline$\sigma_{\text {capt }}$ Am-243 & 0.834 & 0.834 & $5.0 \%$ \\
\hline$\sigma_{\text {capt }}$ Mo-95 & 1.032 & 1.063 & $3.8 \%$ \\
\hline$\sigma_{\text {capt }}$ Mo-97 & 0.968 & 0.993 & $4.4 \%$ \\
\hline$\sigma_{\text {capt }}$ Ru-101 & 1.101 & 1.095 & $3.6 \%$ \\
\hline$\sigma_{\text {capt }}$ Pd-105 & 0.852 & 0.845 & $4.0 \%$ \\
\hline$\sigma_{\text {capt }}$ Cs-133 & 0.878 & $\mathbf{0 . 8 2 7}$ & $4.7 \%$ \\
\hline$\sigma_{\text {capt }} \mathrm{Nd}-145$ & 0.955 & 0.936 & $3.8 \%$ \\
\hline$\sigma_{\text {capt }}$ Sm-149 & 0.915 & 0.908 & $3.1 \%$ \\
\hline
\end{tabular}

Table V: C/E's for PROFIL-2 irradiation experiment.

\begin{tabular}{||l|c|c|c||}
\hline \hline Data Type & VII.0 & VII.1 & Exp. Unc. \\
\hline$\sigma_{\text {capt }}$ U-235 & 0.967 & 0.967 & $1.7 \%$ \\
\hline$\sigma_{\text {capt }}$ U-238 & 0.985 & 0.985 & $2.3 \%$ \\
\hline$\sigma_{\text {capt }}$ Np-237 & 0.944 & 0.941 & $3.6 \%$ \\
\hline$\sigma_{\text {capt }}$ Pu-238 & 1.341 & 1.181 & $4.0 \%$ \\
\hline$\sigma_{\text {capt }}$ Pu-239 & 0.922 & 0.922 & $3.0 \%$ \\
\hline$\sigma_{\text {capt }}$ Pu-240 & 0.973 & 0.961 & $2.2 \%$ \\
\hline$\sigma_{\text {capt }}$ Pu-242 & 1.054 & 1.114 & $4.3 \%$ \\
\hline$\sigma_{\text {capt }}$ Am-241 & 1.018 & 1.029 & $1.7 \%$ \\
\hline$\sigma_{\text {capt }}$ Cm-244 & 1.101 & 0.956 & $2.0 \%$ \\
\hline$\sigma_{\text {capt }}$ Pd-106 & 0.939 & 0.939 & $2.0 \%$ \\
\hline$\sigma_{\text {capt }}$ Nd-143 & 0.937 & 0.937 & $2.0 \%$ \\
\hline$\sigma_{\text {capt }}$ Nd-144 & 0.935 & 0.928 & $2.0 \%$ \\
\hline$\sigma_{\text {capt }}$ Sm-147 & 0.894 & 0.894 & $2.0 \%$ \\
\hline$\sigma_{\text {capt }}$ Sm-151 & 1.094 & 1.085 & $2.0 \%$ \\
\hline$\sigma_{\text {capt }}$ Eu-153 & $\mathbf{0 . 9 2 4}$ & $\mathbf{0 . 9 5 4}$ & $2.0 \%$ \\
\hline \hline
\end{tabular}


Report on INL Activities for Uncertainty Reduction Analysis of FY11

September 2011

Table VI: C/E's for TRAPU 1 irradiated fuel pin.

\begin{tabular}{||c|c|c|c||}
\hline \multirow{2}{*}{ Isotope } & \multicolumn{3}{|c|}{ TRAPU 1 } \\
\cline { 2 - 4 } & VII.0 & VII.1 & Exp. Unc. \\
\hline U-234 & 1.006 & 1.004 & $\pm 3.9 \%$ \\
\hline U-235 & 1.001 & 1.002 & $\pm 0.4 \%$ \\
\hline U-236 & $\mathbf{0 . 9 7 2}$ & $\mathbf{0 . 9 7 1}$ & $\pm 0.8 \%$ \\
\hline Np-237 & $\mathbf{0 . 9 7 0}$ & $\mathbf{0 . 8 7 9}$ & $\pm 6.8 \%$ \\
\hline Pu-238 & 1.004 & $\mathbf{0 . 9 9 2}$ & $\pm 1.5 \%$ \\
\hline Pu-239 & 1.031 & 1.034 & $\pm 0.6 \%$ \\
\hline Pu-240 & 1.003 & 1.007 & $\pm 0.6 \%$ \\
\hline Pu-241 & 1.011 & 1.004 & $\pm 0.6 \%$ \\
\hline Pu-242 & 1.036 & 1.028 & $\pm 0.8 \%$ \\
\hline Am-241 & $\mathbf{0 . 9 7 9}$ & $\mathbf{0 . 9 7 5}$ & $\pm 3.2 \%$ \\
\hline Am242M & 1.009 & 1.016 & $\pm 3.8 \%$ \\
\hline Am-243 & $\mathbf{0 . 9 7 8}$ & 1.025 & $\pm 2.6 \%$ \\
\hline Cm-242 & 1.035 & 0.984 & $\pm 3.9 \%$ \\
\hline Cm-243 & - & - & - \\
\hline Cm-244 & 0.843 & 0.882 & $\pm 2.1 \%$ \\
\hline
\end{tabular}

Table VII: C/E’s for TRAPU 2 irradiated fuel pin.

\begin{tabular}{||c|c|c|c||}
\hline \multirow{2}{*}{ Isotope } & \multicolumn{3}{|c|}{ TRAPU 2 } \\
\cline { 2 - 4 } & VII.0 & VII.1 & Exp. Unc. \\
\hline U-234 & $\mathbf{1 . 0 2 3}$ & $\mathbf{1 . 0 2 6}$ & $\pm 3.8 \%$ \\
\hline U-235 & $\mathbf{1 . 0 2 0}$ & $\mathbf{1 . 0 2 1}$ & $\pm \mathbf{0 . 4} \%$ \\
\hline U-236 & $\mathbf{0 . 9 9 5}$ & $\mathbf{0 . 9 9 2}$ & $\pm 1.0 \%$ \\
\hline Np-237 & $\mathbf{0 . 9 6 3}$ & $\mathbf{0 . 9 8 8}$ & $\pm 3.3 \%$ \\
\hline Pu-238 & $\mathbf{0 . 9 9 0}$ & $\mathbf{0 . 9 9 8}$ & $\pm 1.0 \%$ \\
\hline Pu-239 & 1.012 & $\mathbf{1 . 0 1 4}$ & $\pm \mathbf{0 . 5} \%$ \\
\hline Pu-240 & $\mathbf{0 . 9 8 4}$ & $\mathbf{0 . 9 8 5}$ & $\pm 0.6 \%$ \\
\hline Pu-241 & $\mathbf{0 . 9 9 2}$ & $\mathbf{0 . 9 8 8}$ & $\pm 0.6 \%$ \\
\hline Pu-242 & $\mathbf{1 . 0 1 0}$ & $\mathbf{1 . 0 0 3}$ & $\pm \mathbf{0 . 6} \%$ \\
\hline Am-241 & $\mathbf{0 . 9 8 6}$ & $\mathbf{0 . 9 8 3}$ & $\pm 3.9 \%$ \\
\hline Am242M & $\mathbf{1 . 0 3 9}$ & $\mathbf{1 . 0 4 9}$ & $\pm 4.3 \%$ \\
\hline Am-243 & $\mathbf{0 . 9 5 9}$ & $\mathbf{1 . 0 1 0}$ & $\pm 3.1 \%$ \\
\hline Cm-242 & 1.017 & $\mathbf{0 . 9 6 4}$ & $\pm 3.1 \%$ \\
\hline Cm-243 & $\mathbf{0 . 4 8 3}$ & $\mathbf{1 . 1 0 4}$ & $\pm 3.1 \%$ \\
\hline Cm-244 & $\mathbf{0 . 9 4 6}$ & $\mathbf{0 . 9 9 6}$ & $\pm 2.3 \%$ \\
\hline
\end{tabular}


Table VIII: C/E's for TRAPU 3 irradiated fuel pin.

\begin{tabular}{||c|c|c|c||}
\hline \multirow{2}{*}{ Isotope } & \multicolumn{3}{|c|}{ TRAPU 3 } \\
\cline { 2 - 4 } & VII.0 & VII.1 & Exp. Unc. \\
\hline U-234 & 1.065 & 1.067 & $\pm 4.6 \%$ \\
\hline U-235 & 1.019 & 1.019 & $\pm 0.4 \%$ \\
\hline U-236 & $\mathbf{0 . 9 9 2}$ & $\mathbf{0 . 9 9 1}$ & $\pm 0.9 \%$ \\
\hline Np-237 & $\mathbf{0 . 9 0 8}$ & $\mathbf{0 . 9 1 5}$ & $\pm 3.2 \%$ \\
\hline Pu-238 & 1.013 & 1.001 & $\pm 1.6 \%$ \\
\hline Pu-239 & 1.018 & 1.020 & $\pm 0.4 \%$ \\
\hline Pu-240 & $\mathbf{0 . 9 9 8}$ & $\mathbf{1 . 0 0 2}$ & $\pm 0.6 \%$ \\
\hline Pu-241 & 1.004 & $\mathbf{0 . 9 9 9}$ & $\pm 0.6 \%$ \\
\hline Pu-242 & 1.009 & 1.003 & $\pm 0.6 \%$ \\
\hline Am-241 & $\mathbf{0 . 9 9 1}$ & $\mathbf{0 . 9 8 7}$ & $\pm 2.6 \%$ \\
\hline Am242M & 1.021 & 1.031 & $\pm 3.1 \%$ \\
\hline Am-243 & 1.000 & 1.050 & $\pm 2.5 \%$ \\
\hline Cm-242 & $\mathbf{1 . 0 1 1}$ & $\mathbf{0 . 9 5 9}$ & $\pm 2.7 \%$ \\
\hline Cm-243 & $\mathbf{0 . 4 9 0}$ & $\mathbf{1 . 1 0 6}$ & $\pm 3.2 \%$ \\
\hline Cm-244 & $\mathbf{0 . 9 6 1}$ & $\mathbf{1 . 0 0 9}$ & $\pm 1.8 \%$ \\
\hline \hline
\end{tabular}

\subsection{COSMO Configuration in MUSE-4 Benchmark}

The PROFIL and TRAPU experiments can also provide information on fission cross sections. In the case of PROFIL the experimental results provide the Nd isotope build-up in the actinide samples. If the fission product yield is well known, an estimate can be made for the fission cross section. Nevertheless, the knowledge of the fission yields is based on the fission cross sections, so this can be a tautological situation. In the case of TRAPU, the fission information comes through the sensitivity to this cross section to the buildup of the isotopes.

A more accurate way to gather information on fission cross sections from elemental experiments is through the analysis of fission spectral indices. In this case, fission reaction rates of actinides are measured against a standard, in particular ${ }^{235} \mathrm{U}$ fission. If the measurements are done in the center of a reactor in a well characterized spectrum, indirect effects are minimal and the result can be directly related to the actinide fission cross section. This is the situation for the COSMO experimental campaign, part of the MUSE-4 benchmark project [5] performed at the French zero power fast spectrum facility MASURCA, where different actinide fission spectral indices were measured.

The MUSE-4 benchmark project, organized by OECD/NEA, was performed for studying the physics of accelerator-driven subcritical systems (ADS). The benchmark model was oriented to compare simulation predictions based on available codes and nuclear data libraries with experimental data related to TRU transmutation, criticality constants and time evolution of the neutronic flux following source variation, within liquid metal fast subcritical systems.

A set of experiments were performed in MASURCA reactor which can be configured as critical or subcritical by loading a different number of fuel tubes. The benchmark consists of three configurations. One of configurations is called COSMO (Figure 9), which is a very simple and symmetric critical configuration and has no external source, vacuum tube nor lead buffer. 


\section{Report on INL Activities for Uncertainty Reduction Analysis of FY11}

September 2011

14

The experiment was analyzed based upon the benchmark specifications provided in Ref. [5] and results are shown in Table IX. We conclude from these results that ENDF/B-VII. $1^{238,240} \mathrm{Pu}$ fission cross sections have improved while ${ }^{242} \mathrm{Pu}$ fission cross section has not.

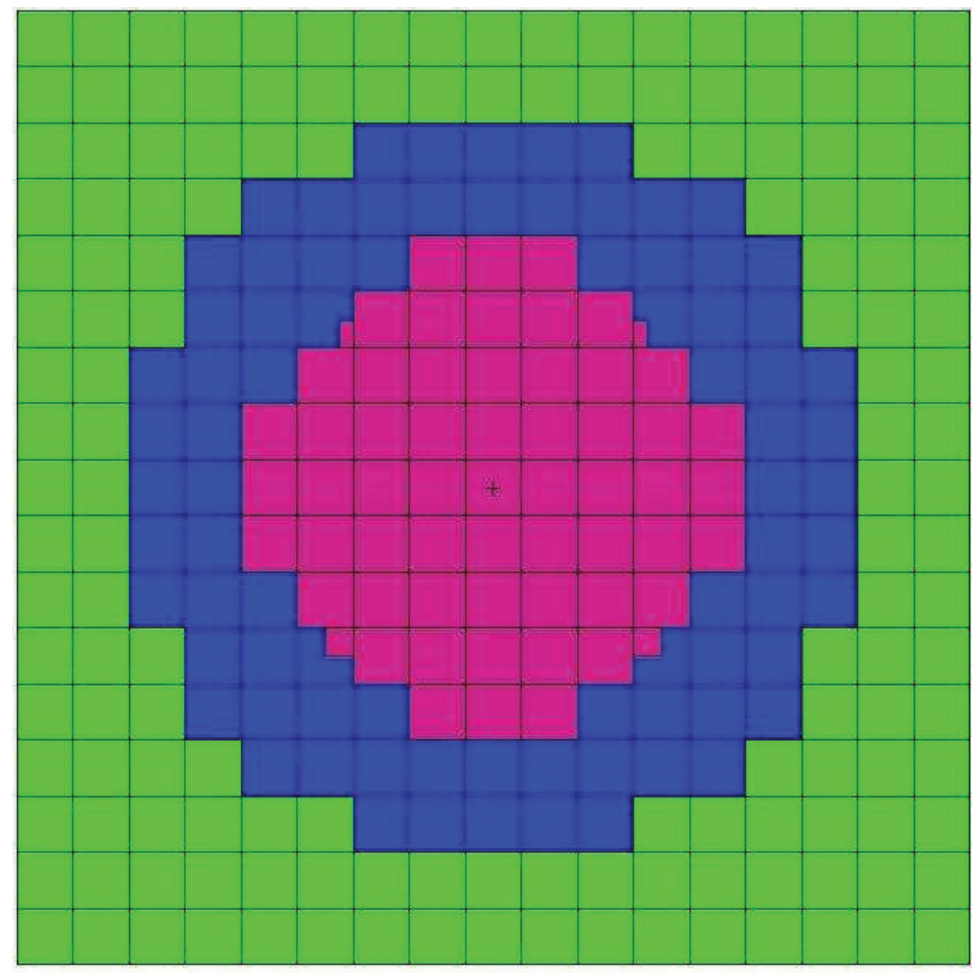

Figure 9: Radial view of COSMO configuration modeled by MCNP5

Table IX: C/E's for spectral indices in COSMO configuration

\begin{tabular}{|c|c|c|c|}
\hline \multirow{2}{*}{ Isotope } & \multicolumn{3}{|c|}{ COSMO C/E } \\
\cline { 2 - 4 } & VII.0 & VII.1 & Exp. Unc. \\
\hline$\sigma_{\text {fis }}{ }^{238} \mathrm{U}$ & 0.984 & 0.981 & $1.5 \%$ \\
\hline$\sigma_{\mathrm{fis}}{ }^{237} \mathrm{~Np}$ & 1.005 & 1.004 & $1.5 \%$ \\
\hline$\sigma_{\text {fis }}{ }^{23} \mathrm{Pu}$ & 1.072 & 1.040 & $2.5 \%$ \\
\hline$\sigma_{\mathrm{fis}}{ }^{239} \mathrm{Pu}$ & 0.991 & 0.989 & $1.3 \%$ \\
\hline$\sigma_{\mathrm{fis}}{ }^{240} \mathrm{Pu}$ & 1.051 & 1.028 & $2.3 \%$ \\
\hline$\sigma_{\mathrm{fis}}{ }^{241} \mathrm{Pu}$ & 1.004 & 1.001 & $2.0 \%$ \\
\hline$\sigma_{\text {fis }}{ }^{242} \mathrm{Pu}$ & 1.018 & 1.041 & $2.3 \%$ \\
\hline$\sigma_{\text {fis }}{ }^{241} \mathrm{Am}$ & 1.089 & 1.081 & $2.3 \%$ \\
\hline$\sigma_{\text {fis }}{ }^{243} \mathrm{Am}$ & 1.010 & 1.009 & $2.3 \%$ \\
\hline
\end{tabular}




\section{ADJUSTMENT}

Table $\mathrm{X}$ reports the current $\mathrm{C} / \mathrm{E}$, and related uncertainties, for all experiments analyzed so far, a total of 148. The irradiation experiments do not have separated $\mathrm{C}$ and $\mathrm{E}$ values, with related uncertainties, because they are the results of averaging over several samples. Moreover, some of the experimental uncertainties, provided in the French documentation are likely overestimated because they include some calculational uncertainties. A thorough reevaluation of these experimental uncertainties will be carried out in the next future. Table X, obtained using the ENDF/B-VII.0 cross section libraries, represents the set of $\mathrm{C} / \mathrm{E}$ 's to be used in the final adjustment. However, as it can be seen from Table X, only a limited number (49) of sensitivity coefficient sets is currently available.

For this reason, it was decided to proceed to a partial adjustment using a very well characterized set of experiments, including availability of correlation terms among the selected experiments. This subset of experiments is the one selected and analyzed in the framework of the WPEC OECD/NEA Subgroup 33, of which G. Palmiotti and M. Salvatores are co-coordinators.

The Working Party on Evaluation Cooperation (WPEC) of the OECD Nuclear Energy Agency Nuclear Science Committee has established an International Subgroup (called "Subgroup 33") on "Methods and issues for the combined use of integral experiments and covariance data". In its mandate "it is proposed for this WPEC subgroup to study methods and issues of the combined use of integral experiments and covariance data, with the objective of recommending a set of best and consistent practices in order to improve evaluated nuclear data files. Indication should be provided on how to best exploit existing integral experiments, define new ones if needed, provide trends and feedback to nuclear data evaluators and measurers".

In this framework a practical exercise was defined in order to test the reliability of the cross section adjustment methodology. Following this indication, the set of experiments, with their correlations, the set of isotopes, and the set of reactions selected in this exercise was used for the partial adjustment.

The following experiments were selected:

Jezebel ${ }^{239}$ Pu configuration: 1 critical mass, 3 spectral indices: F28/F25, F49/F25, F37/F25,

${ }^{240} \mathrm{Pu}$ configuration: 1 critical mass,

Flattop Pu configuration: 1 critical mass, 2 spectral indices: F28/F25, F37/F25,

ZPR6-7 standard configuration: 1 critical mass, 3 spectral indices: F28/F25, F49/F25, C28/F25,

High ${ }^{240} \mathrm{Pu}$ content: 1 critical mass,

ZPPR9 1 critical mass, 3 spectral indices: F28/F25, F49/F25, C28/F25,

$2 \mathrm{Na}$ voids: central void and leakage-dominated configurations,

JOYO 1 critical mass.

The following isotopes were selected:

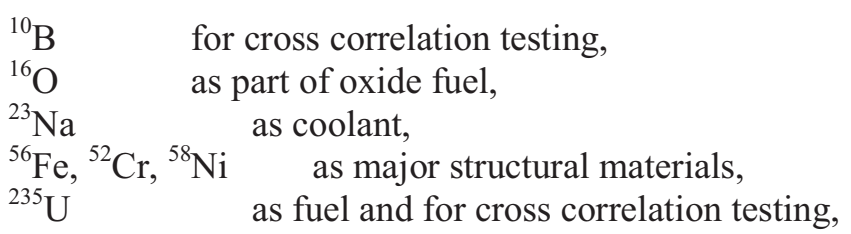




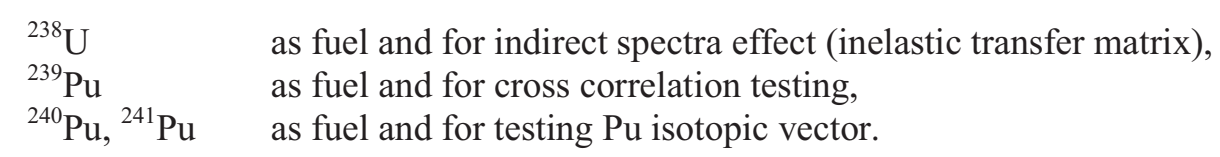

The following cross sections were considered for adjustment:

Elastic scattering infinite-dilution cross section,

Total inelastic scattering infinite-dilution cross section,

Capture infinite-dilution cross section (this includes $10 \mathrm{~B}(\mathrm{n}, \alpha)$ reaction),

Fission infinite-dilution cross section,

Average prompt fission neutron multiplicity (Nu-bar),

Normalized prompt fission neutron spectrum,

Average cosine of elastically scattered neutrons (Mu-bar).

The ERANOS [6] code system that was used to compute the sensitivity coefficients, at the moment does not provide data for the prompt neutron fission spectrum and the Mu-bar. A modification was made in the code system so that the fission spectrum sensitivity coefficients are now computed. The capability for Mu-bar sensitivity coefficients will be implemented lately, as this reaction does not play a significant role in our adjustment.

The experiments were analyzed with ENDF/B-VII data and an adjustment was carried out using the 33 energy groups COMMARA 2.0 covariance matrix provided by BNL with work performed in the complementary FC R\&D Work Package on covariance evaluation. The $\mathrm{C} / \mathrm{E}$ before and after adjustment are shown in Table XI. The normalized (i. e. divided by number of degree of freedom) $\chi^{2}$ obtained after the adjustment was equal to 0.41 , which is exceedingly good. This is the result of the remarkably satisfying new $\mathrm{C} / \mathrm{E}$ obtained after the adjustment with modification of cross sections consistent with the initial uncertainties provided by the COMMARA 2.0 covariance matrix.

Table XII through XVI show the cross sections (and on how much they contribute) that most affect the adjustment of selected experiments. Table XVII through XX illustrate the most significant changes in cross sections, that includes ${ }^{235} \mathrm{U}$ capture, ${ }^{238} \mathrm{U}$ inelastic, ${ }^{239} \mathrm{Pu}$ inelastic and fission spectrum. Most importantly these tables show also the original uncertainty on cross section and that after adjustment. These are the quantities that are more relevant to this work as they will produce, when used in an uncertainty evaluation, significant reductions. In fact one can observe that initial uncertainties on cross sections are reduced by more than a factor two (e. g. ${ }^{238} \mathrm{U}$ inelastic and ${ }^{235} \mathrm{U}$ capture). 
Report on INL Activities for Uncertainty Reduction Analysis of FY11

September 2011

Table X. Final C/E table, with related uncertainty, to be used in the final adjustment. Information on current availability and method used for sensitivity coefficient computation is also provided.

\begin{tabular}{|c|c|c|c|c|c|}
\hline $\begin{array}{c}\text { Experiment } \\
\text { Name }\end{array}$ & $\mathrm{C} \pm$ Unc. & $\mathbf{E} \pm$ Unc. & $\mathbf{C} / \mathbf{E} \pm$ Unc. & $\begin{array}{c}\text { Sens. } \\
\text { Coeff. } \\
\text { Yes/No }\end{array}$ & $\begin{array}{l}\text { Method of } \\
\text { Sens. Coeff. } \\
\text { a) }\end{array}$ \\
\hline GODIVA Keff & $0.99983 \pm 9 \mathrm{pcm}$ & $1.00000 \pm 200 \mathrm{pcm}$ & $0.99983 \pm 201 p c m$ & yes & Tr. \\
\hline $\begin{array}{c}\text { GODIVA } \\
\text { F28/F25 }\end{array}$ & $0.1576 \pm 0.3 \%$ & $0.1650 \pm 1.2 \%$ & $0.955 \pm 1.3 \%$ & yes & Tr. \\
\hline $\begin{array}{l}\text { GODIVA } \\
\text { F37/F25 }\end{array}$ & $0.8297 \pm 0.2 \%$ & $0.8370 \pm 1.6 \%$ & $0.991 \pm 1.6 \%$ & yes & Tr. \\
\hline $\begin{array}{l}\text { GODIVA } \\
\text { F49/F25 }\end{array}$ & $1.3823 \pm 0.2 \%$ & $1.4020 \pm 1.8 \%$ & $0.986 \pm 1.8 \%$ & yes & Tr. \\
\hline JEZEBEL Keff & $0.99986 \pm 9 \mathrm{pcm}$ & $1.00000 \pm 200 \mathrm{pem}$ & $0.99986 \pm 201 p c m$ & yes & Tr. \\
\hline $\begin{array}{l}\text { JEZEBEL } \\
\text { F28/F25 }\end{array}$ & $0.2084 \pm 0.4 \%$ & $0.2133 \pm 1.1 \%$ & $0.977 \pm 1.4 \%$ & yes & Tr. \\
\hline $\begin{array}{c}\text { JEZEBEL } \\
\text { F37/F25 }\end{array}$ & $0.9707 \pm 0.1 \%$ & $0.9835 \pm 1.4 \%$ & $0.987 \pm 1.4 \%$ & yes & Tr. \\
\hline $\begin{array}{l}\text { JEZEBEL } \\
\text { F49/F25 }\end{array}$ & $1.4248 \pm 0.1 \%$ & $1.4609 \pm 0.9 \%$ & $0.975 \pm 0.9 \%$ & yes & Tr. \\
\hline $\begin{array}{c}\text { JEZEBEL Pu40 } \\
\text { Keff }\end{array}$ & $0.99981 \pm 9 \mathrm{pcm}$ & $1.00000 \pm 200 \mathrm{pcm}$ & $0.99981 \pm 201 p c m$ & yes & Tr. \\
\hline Np Sphere Keff & $0.99700 \pm 30 \mathrm{pcm}$ & $1.00260 \pm 360 \mathrm{pem}$ & $0.99441 \pm 365 p \mathrm{pm}$ & yes & Tr. \\
\hline FLATTOP Keff & $1.00097 \pm 18 \mathrm{pcm}$ & $1.00000 \pm 300 \mathrm{pcm}$ & $1.00097 \pm 302 \mathrm{pcm}$ & yes & Tr. \\
\hline $\begin{array}{l}\text { FLATTOP } \\
\text { F28/F25 }\end{array}$ & $0.1767 \pm 0.7 \%$ & $0.1799 \pm 1.1 \%$ & $0.982 \pm 1.8 \%$ & yes & Tr. \\
\hline $\begin{array}{l}\text { FLATTOP } \\
\text { F37/F25 }\end{array}$ & $0.8523 \pm 0.2 \%$ & $0.8561 \pm 1.4 \%$ & $0.996 \pm 1.5 \%$ & yes & Tr. \\
\hline BIGTEN Keff & $1.00452 \pm 7 \mathrm{pcm}$ & $1.0045 \pm 70 \mathrm{pcm}$ & $1.00002 \pm 71 \mathrm{pcm}$ & yes & Tr. \\
\hline $\begin{array}{l}\text { BIGTEN } \\
\text { F28/F25 }\end{array}$ & $0.03540 \pm 0.1 \%$ & $0.03739 \pm 0.9 \%$ & $0.947 \pm 0.9 \%$ & yes & Tr. \\
\hline $\begin{array}{l}\text { BIGTEN } \\
\text { F37/F25 }\end{array}$ & $0.3116 \pm 0.5 \%$ & $0.3223 \pm 0.9 \%$ & $0.967 \pm 1.3 \%$ & yes & Tr. \\
\hline $\begin{array}{l}\text { BIGTEN } \\
\text { F49/F25 }\end{array}$ & $1.1630 \pm 0.3 \%$ & $1.1936 \pm 0.7 \%$ & $0.974 \pm 0.9 \%$ & yes & Tr. \\
\hline ZPR6/6A Keff & $1.00050 \pm 10 \mathrm{pcm}$ & $1.00174 \pm 94 \mathrm{pcm}$ & $0.99876 \pm 96 \mathrm{pcm}$ & yes & Dif. \\
\hline ZPR6/7 Keff & $1.00094 \pm 7 \mathrm{pcm}$ & $1.00051 \pm 230 \mathrm{pcm}$ & $1.00043 \pm 230 \mathrm{pcm}$ & yes & Dif. \\
\hline $\begin{array}{l}\text { ZPR6/7 } \\
\text { F49/F25 }\end{array}$ & $0.9093 \pm 0.7 \%$ & $0.9435 \pm 2.1 \%$ & $0.964 \pm 2.5 \%$ & yes & Dif. \\
\hline $\begin{array}{l}\text { ZPR6/7 } \\
\text { F28/F25 } \\
\end{array}$ & $0.0224 \pm 0.9 \%$ & $0.0223 \pm 3.0 \%$ & $1.004 \pm 3.5 \%$ & yes & Dif. \\
\hline $\begin{array}{c}\text { ZPR6/7 } \\
\text { C28/F25 } \\
\end{array}$ & $0.1336 \pm 0.6 \%$ & $0.1323 \pm 2.4 \%$ & $1.010 \pm 2.7 \%$ & yes & Dif. \\
\hline $\begin{array}{c}\text { ZPR6/7 Pu40 } \\
\text { Keff } \\
\end{array}$ & $1.00017 \pm 11 \mathrm{pcm}$ & $1.00080 \pm 220 \mathrm{pcm}$ & $0.99937 \pm 221 \mathrm{pcm}$ & yes & Dif. \\
\hline COSMO Keff & $1.00607 \pm 12 \mathrm{pcm}$ & $0.99870 \pm 150 \mathrm{pcm}$ & $1.00738 \pm 152 \mathrm{pcm}$ & yes & Dif. \\
\hline $\begin{array}{l}\text { COSMO } \\
\text { F28/F25 } \\
\end{array}$ & & & $0.984 \pm 2.1 \%$ & yes & Dif. \\
\hline $\begin{array}{l}\text { COSMO } \\
\text { F37/F25 } \\
\end{array}$ & & & $1.005 \pm 1.5 \%$ & yes & Dif. \\
\hline
\end{tabular}


Report on INL Activities for Uncertainty Reduction Analysis of FY11

September 2011

18

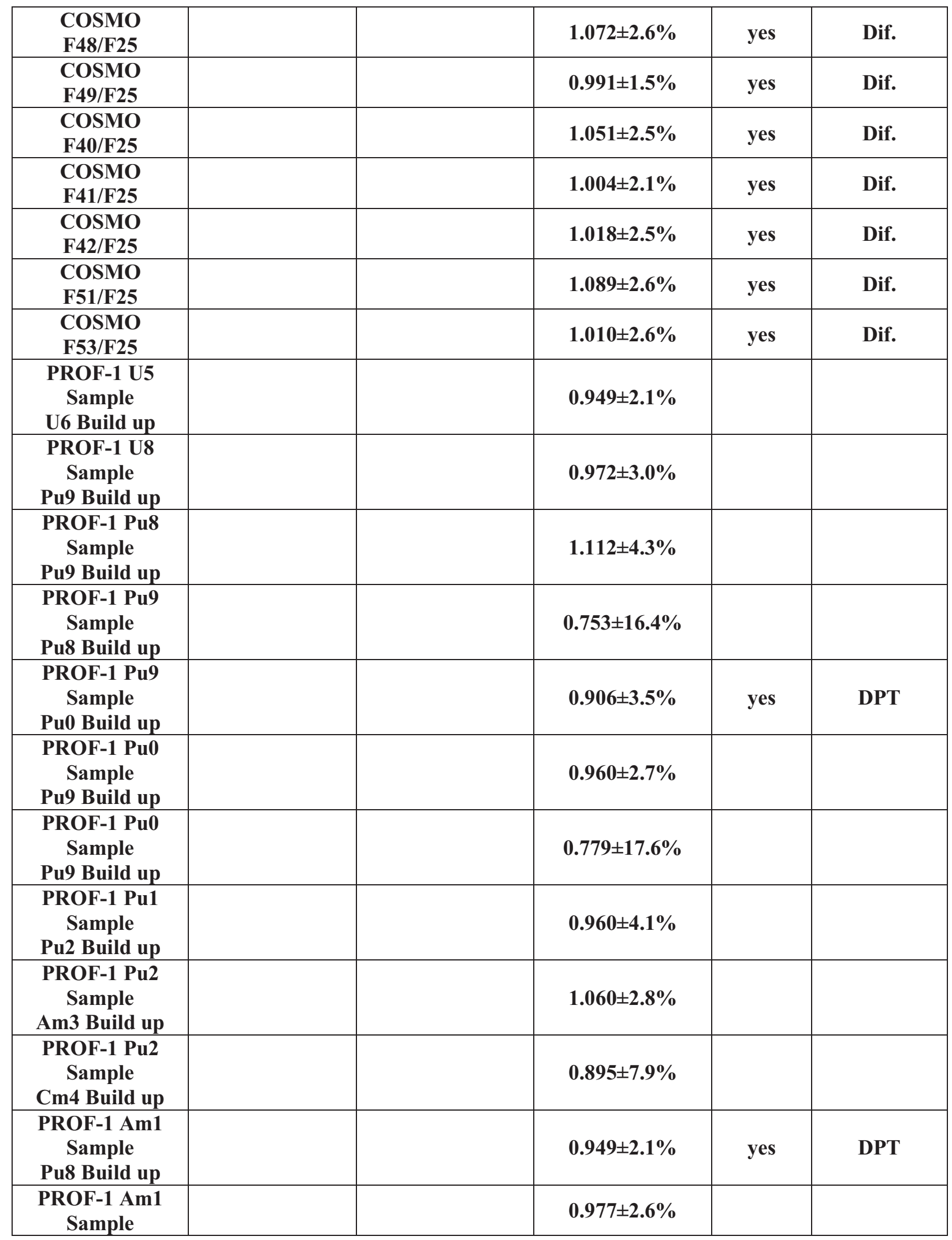


Report on INL Activities for Uncertainty Reduction Analysis of FY11

September 2011

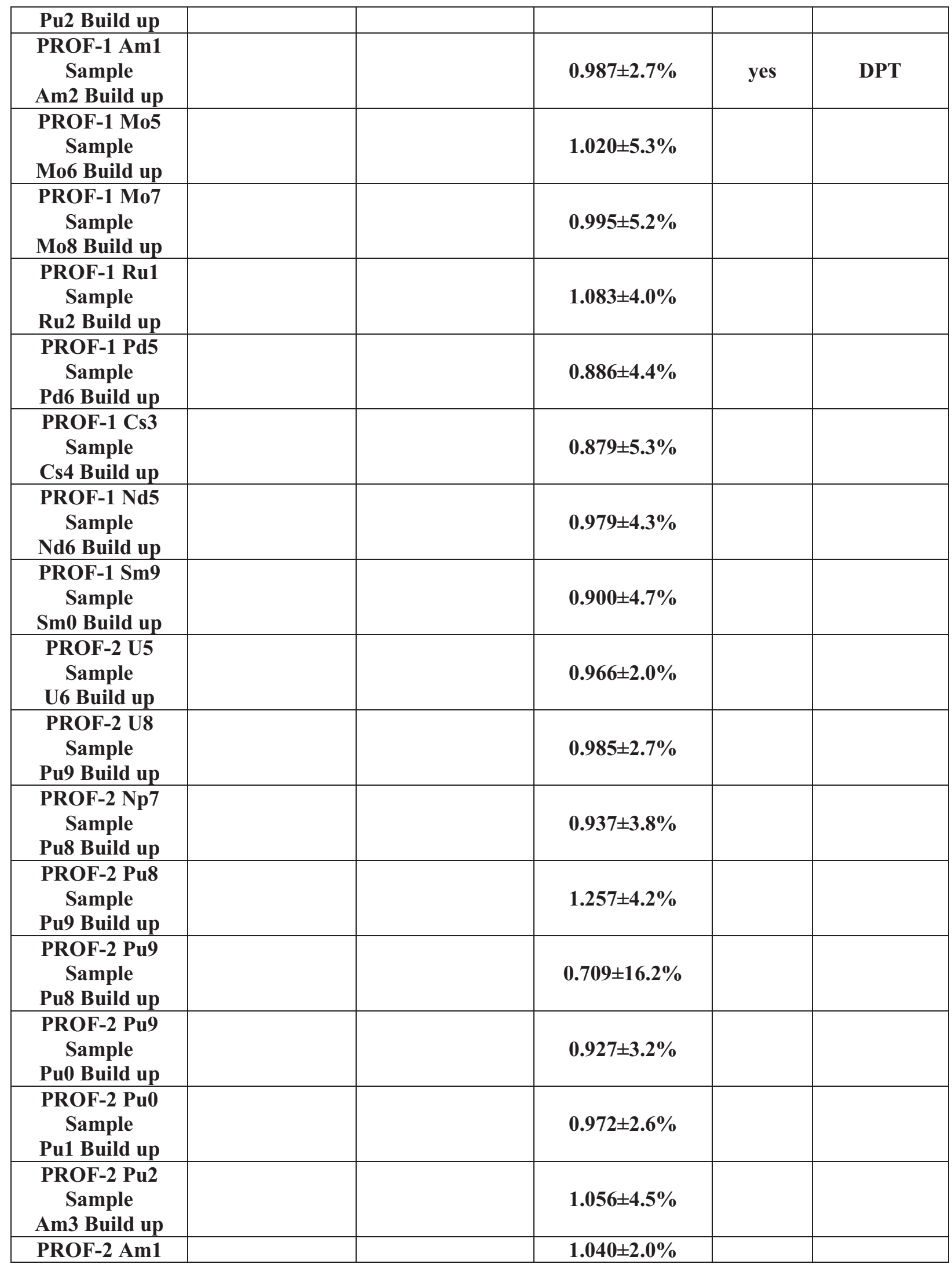


Report on INL Activities for Uncertainty Reduction Analysis of FY11

September 2011

20

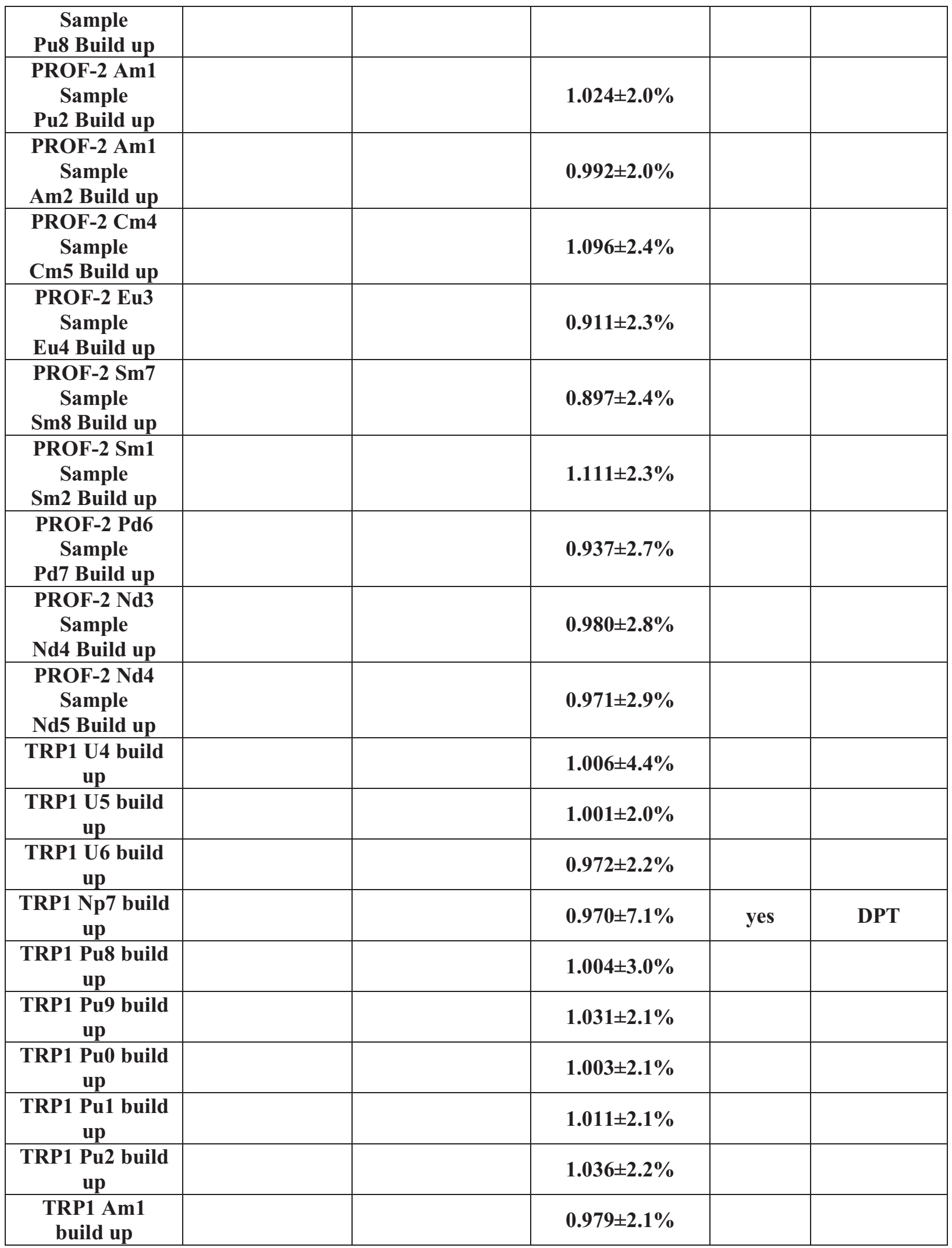


Report on INL Activities for Uncertainty Reduction Analysis of FY11

September 2011

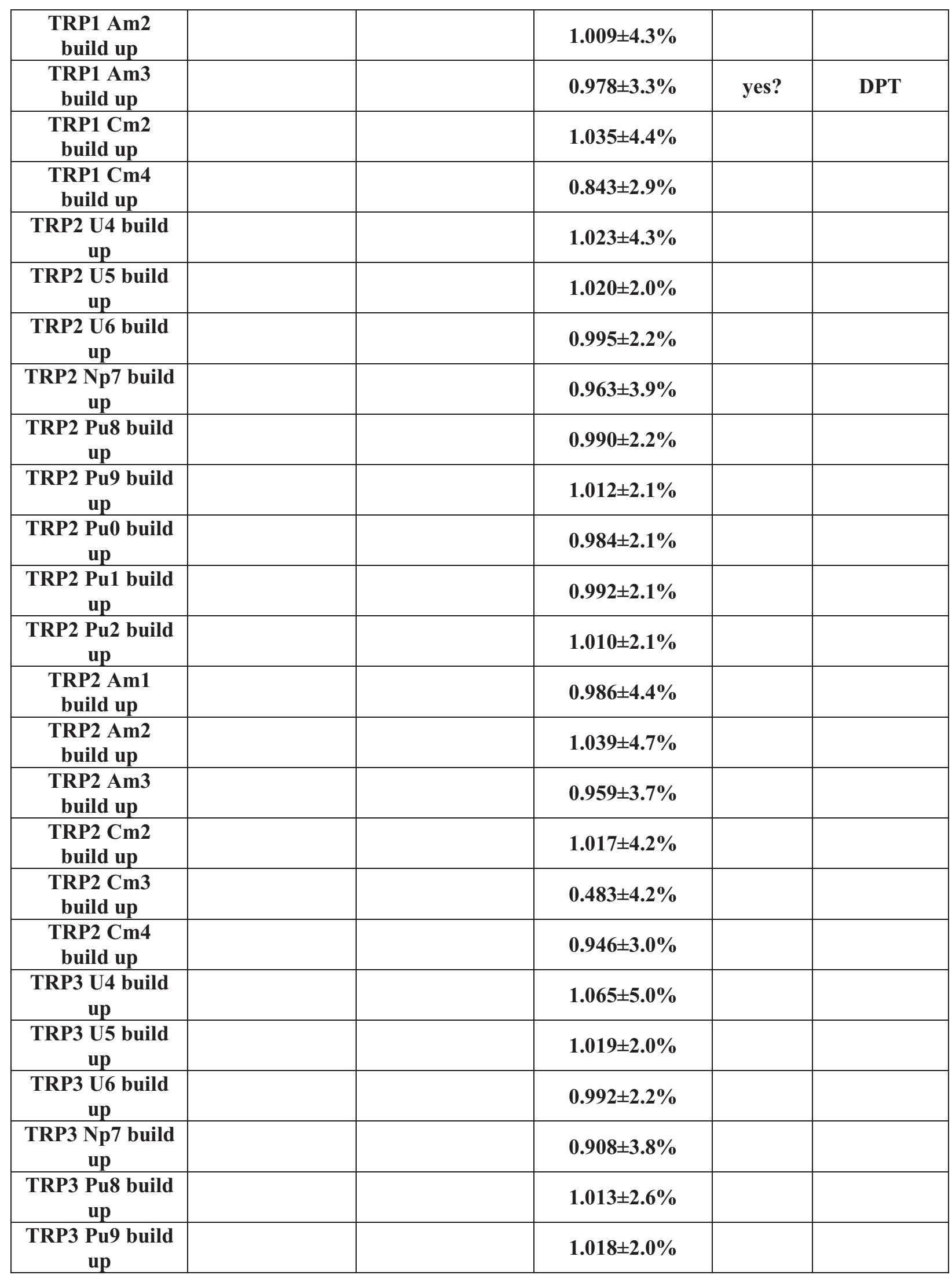


Report on INL Activities for Uncertainty Reduction Analysis of FY11

September 2011

22

\begin{tabular}{|c|c|c|c|c|c|}
\hline $\begin{array}{c}\text { TRP3 Pu0 build } \\
\text { up }\end{array}$ & & & $0.998 \pm 2.1 \%$ & & \\
\hline $\begin{array}{c}\text { TRP3 Pu1 build } \\
\text { up } \\
\end{array}$ & & & $1.004 \pm 2.1 \%$ & & \\
\hline $\begin{array}{c}\text { TRP3 Pu2 build } \\
\text { up }\end{array}$ & & & $1.009 \pm 2.1 \%$ & & \\
\hline $\begin{array}{c}\text { TRP3 Am1 } \\
\text { build up }\end{array}$ & & & $0.991 \pm 3.3 \%$ & & \\
\hline $\begin{array}{l}\text { TRP3 Am2 } \\
\text { build up }\end{array}$ & & & $1.021 \pm 3.7 \%$ & & \\
\hline $\begin{array}{l}\text { TRP3 Am3 } \\
\text { build up }\end{array}$ & & & $1.000 \pm 3.2 \%$ & & \\
\hline $\begin{array}{l}\text { TRP3 Cm2 } \\
\text { build up }\end{array}$ & & & $1.011 \pm 3.4 \%$ & & \\
\hline $\begin{array}{l}\text { TRP3 Cm3 } \\
\text { build up }\end{array}$ & & & $0.490 \pm 3.8 \%$ & & \\
\hline $\begin{array}{l}\text { TRP3 Cm4 } \\
\text { build up }\end{array}$ & & & $0.961 \pm 2.7 \%$ & & \\
\hline ZPR3/53 Keff & $1.01095 \pm 30 \mathrm{pcm}$ & $1.00170 \pm 90 \mathrm{pcm}$ & $1.00923 \pm 108 \mathrm{pcm}$ & yes & Dif. \\
\hline $\begin{array}{c}\text { ZPR3/53 slope } \\
\text { B10 9"/16" }\end{array}$ & $4.8100 \pm 2.5 \%$ & $4.3459 \pm 3 \%$ & $1.107 \pm 5.8 \%$ & & \\
\hline $\begin{array}{l}\text { ZPR3/53 slope } \\
\text { Pu9 9"/16" }\end{array}$ & $4.2002 \pm 2.6 \%$ & $3.8250 \pm 3 \%$ & $1.098 \pm 6.0 \%$ & & \\
\hline $\begin{array}{l}\text { ZPR3/53 slope } \\
\text { U8 9"/16" }\end{array}$ & $7.3702 \pm 3.2 \%$ & $5.3175 \pm 3 \%$ & $1.386 \pm 7.1 \%$ & & \\
\hline ZPR3/54 Keff & $1.01010 \pm 30 \mathrm{pcm}$ & $0.99810 \pm 170 \mathrm{pcm}$ & $1.01202 \pm 180 \mathrm{pcm}$ & yes & Dif. \\
\hline $\begin{array}{l}\text { ZPR3/54 slope } \\
\text { B10 9"/15" }\end{array}$ & $0.8838 \pm 1.5 \%$ & $0.9677 \pm 3$ & $0.913 \pm 4.2 \%$ & & \\
\hline $\begin{array}{l}\text { ZPR3/54 slope } \\
\text { U5 9"/15" }\end{array}$ & $1.3729 \pm 2.6 \%$ & $1.3883 \pm 3 \%$ & $0.989 \pm 6.0 \%$ & & \\
\hline $\begin{array}{l}\text { ZPR3/54 slope } \\
\text { Pu9 9"/15" }\end{array}$ & $1.0970 \pm 3.2 \%$ & $1.1703 \pm 3 \%$ & $0.937 \pm 7.1 \%$ & & \\
\hline $\begin{array}{l}\text { ZPR3/54 slope } \\
\text { U8 9\%/15" }\end{array}$ & $6.5086 \pm 2.4 \%$ & $5.4132 \pm 3 \%$ & $1.202 \pm 5.7 \%$ & & \\
\hline $\begin{array}{l}\text { CIRAN2A slope } \\
\text { U5 } 40.5 \mathrm{~cm} / 54 \mathrm{~cm}\end{array}$ & $1.3783 \pm 0.6 \%$ & $1.3609 \pm 3 \%$ & $1.013 \pm 3.2 \%$ & & \\
\hline $\begin{array}{l}\text { CIRAN2A slope } \\
\text { U8 } 40.5 \mathrm{~cm} / 51 \mathrm{~cm}\end{array}$ & $2.3131 \pm 1.5 \%$ & $1.9674 \pm 3 \%$ & $1.176 \pm 4.2 \%$ & & \\
\hline 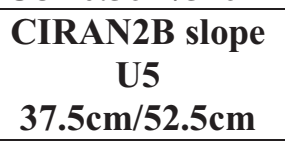 & $0.7135 \pm 1.3 \%$ & $0.7986 \pm 3 \%$ & $0.893 \pm 4.0 \%$ & & \\
\hline $\begin{array}{c}\text { CIRAN2B slope } \\
\text { U8 } \\
37.5 \mathrm{~cm} / \mathbf{5 2 . 5 \mathrm { cm }} \\
\end{array}$ & $6.2985 \pm 2.0 \%$ & $5.1478 \pm 3 \%$ & $1.223 \pm 5 \%$ & & \\
\hline $\begin{array}{c}\text { CIRAN2B slope } \\
\text { Pu9 } \\
37.5 \mathrm{~cm} / 52.5 \mathrm{~cm}\end{array}$ & $0.6882 \pm 1.7 \%$ & $0.7866 \pm 3 \%$ & $0.875 \pm 4.5 \%$ & & \\
\hline $\begin{array}{c}\text { CIRAN2B slope } \\
\text { Np7 }\end{array}$ & $3.3928 \pm 0.9 \%$ & $3.1565 \pm 3 \%$ & $1.075 \pm 3.5 \%$ & & \\
\hline
\end{tabular}


Report on INL Activities for Uncertainty Reduction Analysis of FY11

\begin{tabular}{|c|c|c|c|c|c|}
\hline $37.5 \mathrm{~cm} / 52.5 \mathrm{~cm}$ & & & & & \\
\hline JOYO Keff & $0.99851 \pm 9 \mathrm{pcm}$ & $1.00105 \pm 180 \mathrm{pcm}$ & $0.99746 \pm 181 p c m$ & yes & Tr. \\
\hline ZPPR9 Keff & $1.00028 \pm 3 \mathrm{pcm}$ & $1.00106 \pm 117 \mathrm{pcm}$ & $0.99922 \pm 117 \mathrm{pcm}$ & yes & Tr. \\
\hline ZPPR9 F28/F25 & $0.0201 \pm 0.55 \%$ & $0.0207 \pm 2.7 \%$ & $0.971 \pm 2.9 \%$ & yes & Tr. \\
\hline ZPPR9 F49/F25 & $0.9048 \pm 0.37 \%$ & $0.9225 \pm 2.0 \%$ & $0.981 \pm 2.1 \%$ & yes & Tr. \\
\hline ZPPR9 C28/F25 & $0.1308 \pm 0.33 \%$ & $0.1296 \pm 1.9 \%$ & $1.009 \pm 2.0 \%$ & yes & Tr. \\
\hline ZPPR9 Step3 & $106 \pm 4 \mathrm{pcm}$ & $104 \pm 1.8 \mathrm{pcm}$ & $1.019 \pm 7.7 \%$ & yes & Tr. \\
\hline ZPPR9 Step5 & $109 \pm 4 \mathrm{pcm}$ & $112 \pm 1.9 \mathrm{pcm}$ & $0.973 \pm 7.5 \%$ & yes & Tr. \\
\hline ZPPR10 Keff & $1.00088 \pm 8 \mathrm{pcm}$ & $1.00096 \pm 38 \mathrm{pcm}$ & $0.99992 \pm 41 \mathrm{pcm}$ & yes & Dif. \\
\hline ZPPR10 Step2 & $52 \pm 11 \mathrm{pcm}$ & $76 \pm 0.9 \mathrm{pcm}$ & $0.684 \pm 42.3 \%$ & & \\
\hline ZPPR10 Step3 & $127 \pm 11 \mathrm{pcm}$ & $145 \pm 1.6 \mathrm{pcm}$ & $0.875 \pm 17.4 \%$ & & \\
\hline ZPPR10 Step6 & $187 \pm 11 p c m$ & $187 \pm 2.1 \mathrm{pcm}$ & $1.000 \pm 11.8 \%$ & & \\
\hline ZPPR10 Step9 & $139 \pm 11 \mathrm{pcm}$ & $159 \pm 1.8 \mathrm{pcm}$ & $0.874 \pm 15.9 \%$ & & \\
\hline $\begin{array}{l}\text { ZPPR10 Centr. } \\
\text { Rod }\end{array}$ & $-942 \pm 11 \mathrm{pcm}$ & $-886 \pm 10 p c m$ & $1.063 \pm 2.6 \%$ & & \\
\hline ZPPR15 Keff & $0.99918 \pm 3 p c m$ & $1.00045 \pm 3 \mathrm{pcm}$ & $0.99873 \pm 7 \mathrm{pcm}$ & yes & Dif. \\
\hline $\begin{array}{c}\text { ZPPR15 Centr. } \\
\text { Rod }\end{array}$ & $-160 \pm 4 \mathrm{pcm}$ & $160.8 \pm 1.3 \mathrm{pcm}$ & $0.995 \pm 5.1 \%$ & & \\
\hline $\begin{array}{c}\text { ZPPR15 Centr. } \\
\text { Void }\end{array}$ & $352 \pm 4 \mathrm{pcm}$ & $370 \pm 3 p c m$ & $0.951 \pm 2.4 \%$ & & \\
\hline $\begin{array}{c}\text { ZPR6/10 Keff } \\
\text { Pu/C/SS } \\
\end{array}$ & $1.02700 \pm 20 \mathrm{pcm}$ & $1.00160 \pm 130 \mathrm{pcm}$ & $1.02536 \pm 136 \mathrm{pcm}$ & & \\
\hline $\begin{array}{c}\text { ZPR9/34 Keff } \\
\text { U/Fe }\end{array}$ & $1.00850 \pm 20 \mathrm{pcm}$ & $1.00060 \pm 110 \mathrm{pcm}$ & $1.00790 \pm 117 \mathrm{pcm}$ & & \\
\hline
\end{tabular}

a) Method for sensitivity coefficient computation: Dif. (diffusion theory), Tr. (Transport theory), DPT (Depletion Perturbation Theory). 
Report on INL Activities for Uncertainty Reduction Analysis of FY11 September 2011

Table XI. C/E, with related uncertainty, before (old) and after (new) adjustment.

\begin{tabular}{|c|c|c|c|c|c|}
\hline Experiment & old $\mathbf{C} / \mathbf{E} \pm \sigma$ & new $C / E \pm \sigma$ & Experiment & old $\mathbf{C} / \mathbf{E} \pm \sigma$ & new $C / E \pm \sigma$ \\
\hline $\begin{array}{c}\text { JEZEBEL_Pu239 } \\
\text { Keff }\end{array}$ & $0.9999 \pm 0.002$ & $0.9992 \pm 0.002$ & $\begin{array}{c}\text { ZPR6-7 Pu239 } \\
\text { F49/F25 } \\
\end{array}$ & $0.9638 \pm 0.025$ & $0.9680 \pm 0.006$ \\
\hline $\begin{array}{c}\text { JEZEBEL_Pu239 } \\
\text { F28/F25 }\end{array}$ & $0.9770 \pm \mathbf{0 . 0 1 4}$ & $0.9983 \pm 0.010$ & $\begin{array}{c}\text { ZPR6-7 Pu239 } \\
\text { C28/F25 }\end{array}$ & $1.0098 \pm 0.027$ & $1.0077 \pm 0.009$ \\
\hline $\begin{array}{c}\text { JEZEBEL_Pu239 } \\
\text { F37/F25 }\end{array}$ & $0.9870 \pm 0.014$ & $0.9937 \pm 0.005$ & $\begin{array}{c}\text { ZPR6-7 Pu240 } \\
\text { Keff }\end{array}$ & $0.9994 \pm 0.002$ & $1.0000 \pm 0.001$ \\
\hline $\begin{array}{c}\text { JEZEBEL_Pu239 } \\
\text { F49/F25 }\end{array}$ & $0.9753 \pm 0.009$ & $0.9915 \pm 0.007$ & $\begin{array}{l}\text { ZPPR9 } \\
\text { Keff }\end{array}$ & $0.9992 \pm 0.001$ & $1.0003 \pm 0.001$ \\
\hline$\underset{\text { Keff }}{\text { JEZEBELPP240 }}$ & $0.9998 \pm 0.002$ & $1.0002 \pm 0.002$ & $\begin{array}{c}\text { ZPPR9 } \\
\text { F28/F25 }\end{array}$ & $0.9710 \pm 0.029$ & $0.9835 \pm 0.018$ \\
\hline $\begin{array}{l}\text { FLATTOP } \\
\text { Keff }\end{array}$ & $\begin{array}{l}1.00097 \pm \\
0.003\end{array}$ & $1.0007 \pm 0.002$ & $\begin{array}{c}\text { ZPPR9 } \\
\text { F49/F25 }\end{array}$ & $0.9808 \pm 0.021$ & $0.9849 \pm 0.006$ \\
\hline $\begin{array}{l}\text { FLATTOP } \\
\text { F28/F25 }\end{array}$ & $0.9822 \pm 0.018$ & $1.0009 \pm 0.009$ & $\begin{array}{c}\text { ZPPR9 } \\
\text { C28/F25 }\end{array}$ & $1.0093 \pm 0.020$ & $1.0074 \pm 0.009$ \\
\hline $\begin{array}{l}\text { FLATTOP } \\
\text { F37/F25 }\end{array}$ & $0.9956 \pm 0.015$ & $1.0107 \pm 0.006$ & $\begin{array}{c}\text { ZPPR9 Na Void } \\
\text { Step } 3\end{array}$ & $1.0192 \pm 0.077$ & $1.0282 \pm 0.040$ \\
\hline $\begin{array}{c}\text { ZPR6-7 Pu239 } \\
\text { Keff }\end{array}$ & $1.0004 \pm 0.002$ & $1.0009 \pm 0.001$ & $\begin{array}{c}\text { ZPPR9 Na Void } \\
\text { Step } 5\end{array}$ & $0.9732 \pm 0.075$ & $0.9849 \pm 0.049$ \\
\hline $\begin{array}{c}\text { ZPR6-7 Pu239 } \\
\text { F28/F25 }\end{array}$ & $1.0045 \pm 0.035$ & $1.0017 \pm 0.016$ & $\begin{array}{c}\text { JOYO } \\
\text { Keff }\end{array}$ & $0.9975 \pm 0.002$ & $0.9998 \pm 0.002$ \\
\hline
\end{tabular}

Table XII. Major cross section contributors to adjustment of JEZEBEL $\mathrm{K}_{\text {eff. }}$

\begin{tabular}{|c|c|}
\hline Cross Section & $\begin{array}{c}\text { Contribution } \\
(\text { pcm })\end{array}$ \\
\hline Pu239 $\sigma^{\text {inel }}$ gr. 6 & -116 \\
\hline Pu239 $\chi$ gr. 4 & 102 \\
\hline Pu239 $\sigma^{\text {inel }}$ gr. 7 & -92 \\
\hline Pu239 $\sigma^{\text {inel }}$ gr. 5 & -84 \\
\hline Pu239 $\sigma^{\text {inel }}$ gr. 8 & -65 \\
\hline Pu239 $\chi$ gr. 8 & -63 \\
\hline Pu239 $\chi$ gr. 5 & 59 \\
\hline Total & -66 \\
\hline
\end{tabular}

Table XIII. Major cross section contributors to adjustment of JEZEBEL ${ }^{238 U}$ Fis $/{ }^{235} \mathrm{U}$ Fis. spectral index.

\begin{tabular}{|c|c|}
\hline Cross Section & Contribution (\%) \\
\hline Pu239 $\sigma^{\text {inel }}$ gr. 5 & 0.5 \\
\hline Pu239 $\sigma^{\text {inel }}$ gr. 4 & 0.4 \\
\hline${\text { Pu239 } \sigma^{\text {inel }} \text { gr. 6 }}^{\text {Pu239 } \sigma^{\text {inel }} \text { gr. } 7}$ & 0.3 \\
\hline Pu239 $^{\text {inel }}$ gr. 3 & 0.2 \\
\hline Pu239 $\sigma^{\text {elas }}$ gr. 8 & 0.2 \\
\hline Pu2 & 0.1 \\
\hline Total & 2.2 \\
\hline
\end{tabular}


Table XIV. Major cross section contributors to adjustment of ZPPR-9 $\mathrm{K}_{\text {eff. }}$.

\begin{tabular}{|c|c|}
\hline Cross Section & $\begin{array}{c}\text { Contribution } \\
(\text { pcm })\end{array}$ \\
\hline Pu239 $\chi$ gr. 4 & 92 \\
\hline Pu239 $\chi$ gr. 8 & -54 \\
\hline Pu239 $\chi$ gr. 5 & 50 \\
\hline Pu239 $\chi$ gr. 9 & -40 \\
\hline Pu239 $\chi$ gr. 3 & 35 \\
\hline Pu239 $\chi$ gr. 2 & 32 \\
\hline Pu239 $\sigma^{\text {capt }}$ gr. 16 & $\mathbf{- 3 2}$ \\
\hline Total & 50 \\
\hline
\end{tabular}

Table XV. Major cross section contributors to adjustment of ZPPR-9 Na Void Step 5.

\begin{tabular}{|c|c|}
\hline Cross Section & $\begin{array}{c}\text { Contribution } \\
(\%)\end{array}$ \\
\hline U238 $\sigma^{\text {inel }}$ gr. 4. & 0.2 \\
\hline Pu239 $\sigma^{\text {cap }}$ gr. 16 & 0.2 \\
\hline Pu239 $\sigma^{\text {cap }}$ gr. 18 & -0.2 \\
\hline Pu239 $\chi$ gr. 4 & -0.1 \\
\hline Pu239 $\sigma^{\text {inel }}$ gr. 7 & 0.1 \\
\hline Pu239 $\chi$ gr. 8 & 0.1 \\
\hline Total & 1.2 \\
\hline
\end{tabular}

Table XVI. Major cross section contributors to adjustment of JOYO $\mathrm{K}_{\text {eff. }}$.

\begin{tabular}{|c|c|}
\hline Cross Section & $\begin{array}{l}\text { Contribution } \\
\text { (pcm) }\end{array}$ \\
\hline Pu239 $\chi$ gr. 4 & 43 \\
\hline U235 $\sigma^{\text {cap }}$ gr. 11 & 38 \\
\hline U235 $\sigma^{\text {cap }}$ gr. 10 & 37 \\
\hline U235 $\sigma^{\text {cap }}$ gr. 12 & 35 \\
\hline U235 $\sigma^{\text {cap }}$ gr. 13 & 31 \\
\hline U235 $\sigma^{\text {cap }}$ gr. 14 & 29 \\
\hline Pu239 $\chi$ gr. 8 & -29 \\
\hline Total & 233 \\
\hline
\end{tabular}


Table XVII. Major cross section adjusted: ${ }^{238} \mathrm{U}$ inelastic.

\begin{tabular}{||c|c|c|c||}
\hline \multirow{2}{*}{$\begin{array}{c}\text { Cross } \\
\text { Sect. }\end{array}$} & \multirow{2}{*}{$\begin{array}{c}\text { Adjus. } \\
\%\end{array}$} & \multicolumn{2}{|c|}{$\begin{array}{c}\text { Stand. } \\
\text { Deviat. \% }\end{array}$} \\
\cline { 3 - 4 } & & Initial & Adj. \\
\hline \hline$\sigma^{\text {inel }}$ gr. 3 & -1.5 & 20.1 & 8.1 \\
\hline$\sigma^{\text {inel }}$ gr. 4 & -1.4 & 19.4 & 5.4 \\
\hline$\sigma^{\text {inel }}$ gr. 5 & -1.1 & 20.6 & 8.4 \\
\hline$\sigma^{\text {inel }}$ gr. 6 & -1.2 & 16.9 & 7.3 \\
\hline
\end{tabular}

Table XVIII. Major cross section adjusted: ${ }^{235} \mathrm{U}$ capture.

\begin{tabular}{||c|c|c|c||}
\hline \multirow{2}{*}{ Param. } & \multirow{2}{*}{$\begin{array}{c}\text { Adjus. } \\
\%\end{array}$} & \multicolumn{2}{|c|}{$\begin{array}{c}\text { Stand. } \\
\text { Deviat. \% }\end{array}$} \\
\cline { 3 - 4 } & & Initial & Adj. \\
\hline \hline$\sigma^{\text {cap }}$ gr. 9 & -8.4 & 20.0 & 9.7 \\
\hline$\sigma^{\text {cap }}$ gr. 10 & -8.4 & 20.0 & 9.6 \\
\hline$\sigma^{\text {cap }}$ gr. 11 & -8.4 & 20.0 & 9.7 \\
\hline$\sigma^{\text {cap }}$ gr. 12 & -8.4 & 20.0 & 9.7 \\
\hline$\sigma^{\text {cap }}$ gr. 13 & -8.4 & 20.0 & 9.6 \\
\hline$\sigma^{\text {cap }}$ gr. 14 & -8.4 & 20.0 & 9.6 \\
\hline
\end{tabular}

Table XIX. Major cross section adjusted: ${ }^{239} \mathrm{Pu}$ inelastic.

\begin{tabular}{|c|c|c|c||}
\hline \multirow{2}{*}{$\begin{array}{c}\text { Cross } \\
\text { Sect. }\end{array}$} & \multirow{2}{*}{$\begin{array}{c}\text { Adjus. } \\
\%\end{array}$} & \multicolumn{2}{|c|}{$\begin{array}{c}\text { Stand. } \\
\text { Deviat. \% }\end{array}$} \\
\cline { 3 - 4 } & & Initial & Adj. \\
\hline \hline$\sigma^{\text {inel }}$ gr. 3 & -6.4 & 25.6 & 19.5 \\
\hline$\sigma^{\text {inel }}$ gr. 4 & -7.8 & 19.6 & 11.4 \\
\hline$\sigma^{\text {inel }}$ gr. 5 & -9.7 & 19.0 & 8.8 \\
\hline$\sigma^{\text {inel }}$ gr. 6 & -14.8 & 27.0 & 13.7 \\
\hline$\sigma^{\text {inel }}$ gr. 7 & -17.0 & 32.6 & 18.9 \\
\hline$\sigma^{\text {inel }}$ gr. 8 & -15.7 & 32.7 & 21.3 \\
\hline$\sigma^{\text {cap }}$ gr. 16 & 6.7 & 16.5 & 14.9 \\
\hline$\sigma^{\text {cap }}$ gr. 17 & 6.6 & 16.5 & 14.9 \\
\hline$\sigma^{\text {cap }}$ gr. 18 & 4.3 & 10.7 & 9.7 \\
\hline
\end{tabular}


Table XX. Major cross section adjusted: ${ }^{239} \mathrm{Pu}$ fission spectrum.

\begin{tabular}{|c|c|c|c|}
\hline \multirow{2}{*}{$\begin{array}{c}\text { Cross } \\
\text { Sect. }\end{array}$} & \multirow{2}{*}{$\begin{array}{c}\text { Adjus. } \\
\%\end{array}$} & \multicolumn{2}{|c|}{$\begin{array}{c}\text { Stand. } \\
\text { Deviat. \% }\end{array}$} \\
\cline { 3 - 4 } & & Initial & Adj. \\
\hline$\chi$ gr. 1 & 1.8 & 18.9 & 16.1 \\
\hline$\chi$ gr. 2 & 1.1 & 6.2 & 4.9 \\
\hline$\chi$ gr. 3 & 0.3 & 4.0 & 2.9 \\
\hline$\chi$ gr. 4 & 0.5 & 1.9 & 1.4 \\
\hline$\chi$ gr. 5 & 0.3 & 1.2 & 1.1 \\
\hline$\chi$ gr. 6 & 0.03 & 2.2 & 1.7 \\
\hline$\chi$ gr. 7 & -0.4 & 2.5 & 1.7 \\
\hline$\chi$ gr. 8 & -1.3 & 3.5 & 2.6 \\
\hline$\chi$ gr. 9 & -1.9 & 4.9 & 4.0 \\
\hline$\chi$ gr. 10 & -2.2 & 5.8 & 4.9 \\
\hline$\chi$ gr. 11 & -2.5 & 6.5 & 5.5 \\
\hline$\chi$ gr. 12 & -2.6 & 6.8 & 5.9 \\
\hline$\chi$ gr. 13 & -2.6 & 6.9 & 6.0 \\
\hline$\chi$ gr. 14 & -2.6 & 7.0 & 6.1 \\
\hline
\end{tabular}




\section{CONCLUSIONS}

This report has presented the status of activities performed at INL under the ARC Work Package on "Uncertainty Reduction Analyses" that has as a main goal the reduction of uncertainties associated with nuclear data on neutronic integral parameters of interest for the design of advanced fast reactors under consideration by the ARC program.

First, an analysis of experiments was carried out. For both JOYO (the first Japanese fast reactor) and ZPPR-9 (a large size zero power plutonium fueled experiment performed at ANL-W in Idaho) the performance of ENDF/B-VII.0 is quite satisfying except for the sodium void configurations of ZPPR-9, but for which one has to take into account the approximation of the modeling. In fact, when one uses a more detailed model (calculations performed at ANL in a companion WP) more reasonable results are obtained.

A large effort was devoted to the analysis of the irradiation experiments, PROFIL-1 and -2 and TRAPU, performed at the French fast reactor PHENIX. For these experiments a pre-release of the ENDF/B-VII.1 cross section files was also used, in order to provide validation feedback to the CSWEG nuclear data evaluation community.

In the PROFIL experiments improvements can be observed for the ENDF/B-VII.1 capture data in ${ }^{238} \mathrm{Pu}$, ${ }^{241} \mathrm{Am},{ }^{244} \mathrm{Cm},{ }^{97} \mathrm{Mo},{ }^{151} \mathrm{Sm},{ }^{153} \mathrm{Eu}$, and for ${ }^{240} \mathrm{Pu}(\mathrm{n}, 2 \mathrm{n})$. On the other hand, ${ }^{240,242} \mathrm{Pu},{ }^{95} \mathrm{Mo},{ }^{133} \mathrm{Cs}$ and ${ }^{145} \mathrm{Nd}$ capture $\mathrm{C} / \mathrm{E}$ results are worse. For the major actinides ${ }^{235} \mathrm{U}$ and especially ${ }^{239} \mathrm{Pu}$ capture $\mathrm{C} / \mathrm{E}$ 's are underestimated. For fission products, ${ }^{105,106} \mathrm{Pd},{ }^{143,144} \mathrm{Nd}$ and ${ }^{147,149} \mathrm{Sm}$ are significantly underestimated, while ${ }^{101} \mathrm{Ru}$ and ${ }^{151} \mathrm{Sm}$ are overestimated. Other $\mathrm{C} / \mathrm{E}$ deviations from unity are within the combined experimental and calculated statistical uncertainty. From the TRAPU analysis, the major improvement is in the predicted ${ }^{243} \mathrm{Cm}$ build-up, presumably due to an improved ${ }^{242} \mathrm{Cm}$ capture evaluation. The COSMO experiment was also analyzed in order to provide useful feedback on fission cross sections. It was found that ENDF/B-VII.1 ${ }^{238,240} \mathrm{Pu}$ fission cross sections have improved with respect to VII.0 files while ${ }^{242} \mathrm{Pu}$ fission cross section has not.

One major achievement reported in this deliverable is Table $\mathrm{X}$, which summarizes all the experiments (148) analyzed so far using ENDF/B-VII.0 cross section data and the best modeling available (in most cases Monte Carlo calculations). The table reports $\mathrm{C} / \mathrm{E}$ 's and associated uncertainties. This table represents the basis for performing a thorough adjustment. However, at this moment sensitivity coefficients, needed to carry out the adjustment, have been computed only for a limited set of experiments. For this reason, it was decided to proceed to a partial adjustment using a very well characterized subset (from the original 148) of experiments, including availability of correlation terms among the selected experiments. This subset of experiments is the one selected and analyzed in the framework of the WPEC OECD/NEA Subgroup 33.

The adjustment was performed using the 33 energy group covariance data matrix COMMARA 2.0 and very satisfying results were obtained both in terms of new $\mathrm{C} / \mathrm{E}$ 's after adjustment and $\chi^{2}$ test for statistical consistency. More importantly, the uncertainties of the major cross sections affected in the adjustment $\left({ }^{235} \mathrm{U}\right.$ capture, ${ }^{238} \mathrm{U}$ inelastic, ${ }^{239} \mathrm{Pu}$ inelastic and fission spectrum) show major improvements after adjustment. These are the quantities that are more relevant to this work as they will produce, when used in an uncertainty evaluation, significant reductions.

For next fiscal years the projected activities at INL include:

- Software tools development: 
- Implement computation of anisotropic scattering sensitivity coefficients for both elastic and inelastic scattering. Covariance data are starting to be available for these quantities and they can play a significant role in uncertainty evaluation and data assimilation.

- Finalize rewriting of adjustment code in modern programming language and addition of several features including use of alternate (Bayesian) adjustment methodology.

- Compute remaining experiment sensitivity coefficients. Add all missing type of sensitivity coefficients. Organize data for easy access and use for eventual full adjustment.

- Continue to coordinate activities on OECD/NEA subgroup 33. Participants are performing a three step adjustment exercise using:

1. own initial cross sections, own nuclear data covariances, w/wo integral experiment correlation

2. own initial cross sections, same nuclear data covariances, w/wo integral experiment correlation

3. same initial cross sections, same nuclear data covariances, w/wo integral experiment correlation

- Perform full adjustment in two phases (this is related to issues on iron nuclear data):

- First use all experiments that presents low sensitivity to iron cross sections

- Then use all experiments including those very sensitive to iron cross sections

- Evaluate uncertainty reduction on all reactors of interest and main integral neutronic design parameters using updated covariance data resulting from adjustment process. 


\section{REFERENCES}

[1] X-5 Monte Carlo Team, "MCNP - A General Monte Carlo N-Particle Transport Code, Version 5," LA-UR-03-1987, Los Alamos National Laboratory (2003).

[2] International Handbook of Evaluated Reactor Physics Benchmark Experiments, NEA/NSC/DOC(2006)1, OECD-NEA, March (2009).

[3] A.D’Angelo, F.Cleri, P.Marimbeau, M.Salvatores and J.P.Grouiller, "Analysis of Sample and Fuel Pin Irradiation in PHENIX for Basic Nuclear Data Validation”, Nucl. Sci. and Eng. 105, 244 (1990).

[4] G. Palmiotti, M. Salvatores, and R. N. Hill, "Sensitivity, Uncertainty Assessment, and Target Accuracies Related to Radiotoxicity Evaluation”, Nucl. Sci. Eng. 117, 239 (1994).

[5] Benchmark on Computer Simulation of MASURCA Critical and Subcritical Experiments: MUSE-4 Benchmark, Final Report, NEA/NSC/DOC(2005)23, (2006).

[6] G. Rimpault et al., "The ERANOS Code and Data System for Fast Reactor Neutronics Analyses", Proc. PHYSOR 2002 Conference, Seoul (Korea), October 2002. 